\title{
Do Price Makers or Price Takers Suffer More During an Economic Recession?
}

\author{
Ruiqian Li \\ Eunoia Junior College, Singapore, China
}

\begin{abstract}
The study seeks to understand the relationship between market power and the performance of firms during the recession, as well as its effect on firms' recovery after the recession. Along the way, the effect of firms' sizes is also explored. By analysing the performance of 81 US-based firms from the manufacturing sector, we discover that the market power plays a significant role in both the revenue and profit changes of the firms, while the firm's size is considerably less. Our main finding is that the price takers seem to suffer more during a recession but recover just as fast as the price makers.
\end{abstract}

Keywords: Economic recession, market power, firm's performance

\section{Introduction}

The 2007-2009 recession has been a time of suffering for firms all over the world. While some firms suffered considerably, others have been less severely impacted and continued to thrive. The question therefore is what exactly causes the difference in the performances of firms during a recession? In this paper, we will briefly discuss the effect of market power on the performance of firms during a recession. To simplify the analysis, we only look at the subset of companies that survived a recession. We are studying how different the performances before, during and after the recession is. We will focus on the manufacturing sector in the US, and make use of the data from financial reports from each individual firm included in this paper to investigate how severely they are affected during the recession period, and their ability to recover after the recession. In other words, we are measuring the resilience of firms to recession.

Our work in this paper is deeply related to the debate in the literature on how firms are affected by economic downturns. Crawford, Jin and Simpson (2013) suggest that during a recession, there is a greater fall in labour productivity for small and medium-sized firms as compared to bigger and mature firms. In other literature, it appears that small firms will experience a larger decline in net employment 


\title{
$9^{\text {th }}$ INTERNATIONAL CONFERENCE ON MANAGEMENT , ECONOMICS AND HUMANITIES
}

\author{
26-28 July, 2019 \\ London, United Kingdom
}

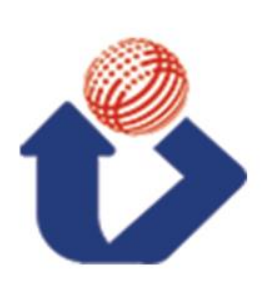

and job creation. (Fort et al. 2013) It has also been shown that financing constraint is one of the main factors leading to the collapse of small firms in a recession. (Duygan-Bump et al. 2014)

In this paper, firms will be separated into two categories, namely the price makers and price takers, which correspond to firms with a large and a small degree of market power in the industry. We use the Lerner Index as the medium of differentiation. In addition, we will also account for the effect of the different sizes of the firms, which are measured by the numbers of employees, on the performances of firms. We believe that by studying how these various factors affect firms' performances, greater insights can be gained in terms of the relationship between market power or size of firms and the performance of firms during the recession.

We will start off with some theoretical analysis of market power and performance of firms. First of all, as a price maker in the industry, a firm with great market power in the industry has the ability to decide the price of a certain good or service. With this ability, the firm is more likely to operate at the profit-maximising point where marginal cost is equal to marginal revenue. Secondly, as a monopoly in the industry, the firm can reap more internal economies of scale to have a lower average cost of production in terms of e.g. raw materials. Hence, the monopolistic firm will have a higher profit with a lower average cost, ceteris paribus. In addition, a monopolistic firm is able to carry out strategic pricing or predatory pricing to deter the potential entry of the new firms to maintain its market power in the long run, which further secures its profitability in the future.

During the period of a recession, the validity of the arguments above may not hold anymore. We have considered five factors which can potentially link a firm's performance to its market power, including the effect of the price elasticity on the goods, unemployment, ability to borrow, the size of the firm, and the complexity of business structure.

Firstly, during a recession, aggregate demand falls, leading to an unexpected surplus in the inventory of the firm. In the next phrase of the business cycle, it is natural for a firm to hire fewer factors of production, so it might reduce its number of employees of the firm. With fewer employees or factors of production, the supply of the goods and services from the firm will hence decrease. This could be more detrimental for big firms as they will have a diminished ability to reap more economies of scale, which means their unit cost of production will rise during the recession period, and their profitability will weaken.

However, increasing unemployment could also bring potential benefit to the price maker. Richard and William (1980) state that market power is inversely related to the elasticity of demand. This could be beneficial for firms with great market power. During the recession, with fewer factors of production, the supply will most likely fall. However, with the demand for goods and services being inelastic, the quantity demanded will fall less proportionately than the rise in price, which will eventually lead to higher total revenue than before, which can potentially offset the rise in the cost of production or even generate higher profit for the firm. In contrast, the profitability of small firms, which faces greater demand elasticity, is likely to worsen during the recession. 


\title{
$9^{\text {th }}$ INTERNATIONAL CONFERENCE ON MANAGEMENT , ECONOMICS AND HUMANITIES
}

\author{
26-28 July, 2019 \\ London, United Kingdom
}

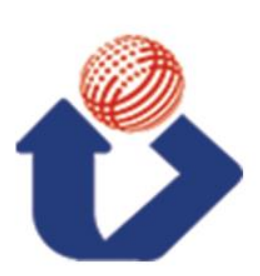

Secondly, the loss in the profitability of small firms due to unemployment may be larger than expected. This is due to the decreasing marginal benefit of labour, which essentially states that the more employees a firm has, the lower the average output of each person, due to the constraints of other resources. Hence, for small firms with fewer employees, the average return of each person is much higher and takes up a higher percentage in the total output of the firm. It can be said that one employee in a small firm is more valuable than one person in a big firm. Since because labour is indivisible, small firms have no choice but to fire more employees than they actually need to. Therefore, during a recession, it is expected that small firms will suffer more from shortage of labour.

Thirdly, during the recession, when firms run into debt, the ability to obtain loans also plays part in the firms' performance. A loan essentially means more working capital for the firm to spare, which can be turned into more revenue and profit, thereby improving further future production and investment. This process sets up a virtuous cycle for firms to minimise the impact of the recession on their performances. A price maker is usually more profitable than a price taker, so it is more likely to repay its debt once the recession ends, and to do so more quickly. Thus, borrowing money is much easier as banks have more confidence in big firms and hence are more willing to lend to them. On the other hand, due to the uncertainty in the profitability of small firms, banks will likely to restrict lending to them in fear of their potential bankruptcies. This mechanism worsens the price takers' performances during a recession.

In addition, the size of firms may also play a role in the firms' performances. Even though Malriuzzu, Walsh and Whelan (2003) state that there is no clear relationship between the size and the performance of firms in the industry of carbonated drinks, which is the industry included in our work, Prasetyantoko and Parmono (2009) claim that bigger firms tend to perform better, especially during the postrecession period, in terms of the recovering of firms. The difference arises from the different focus of the two papers, and Prasetyantoko and Parmono's work is more similar to ours as we both make use of the financial data to access the relationship rather than market shares used in the first paper.

Last but not least, the complexity of business structure will also affect the performance of firms. For large firms, where different departments are highly specialised and independent, it will take time for the board to collate all the information and discuss what the most feasible policy is. However, for small firms, where the structure is flatter, it would take a shorter time for the board to pass the new policy. This could be a potential advantage for the small firms when a quick reaction to the most current situation is needed. With the problem of the time lag in the large firms, the policy may not be as effective as expected because new problems may occur, and the agreed upon policy may not be able to address them all at the same time.

\section{Analysis}

For the purpose of our study, we have chosen the 2007-2009 recession to be our reference. As stated, our paper focuses on firms in the US. This is a deliberate choice, as the 2007-2009 recession started in the US, with the collapse of the real-estate market. Therefore, the US firms and consumers 


\section{$9^{\text {th }}$ INTERNATIONAL CONFERENCE ON MANAGEMENT , ECONOMICS AND HUMANITIES}

were the direct victims of that recession, as well as the first responders. Besides, as the most developed country in the world, the US has a large number of candidates for both price makers and price takers. Hence selecting the US allows us to explore the impact of the recession in a more unbiased manner. Finally, with more financial data available online, the data collection for US firms is more convenient and consistent as compared to other countries. On a final note, we have also chosen the firms in the manufacturing sector, which we believe would respond strongly to any change in the economy or the behaviour of consumers during a recession.

To extract useful data we need, we make use of Stockrow and the financial data of the firms. This way, we obtain key indicators of performances such as revenue and net income. For the purpose of our work, we have chosen to collect and analyse the financial data of the firms from before, during, and after the recession. Our targeted time period is hence from 2003 to 2018, which gives us a good estimation of how differently the firms perform at the three different stages mentioned above. While the Stockrow data is limited to 10 years back, we obtain the missing data directly from the Securities and Exchanges Commission (SEC) website and by extracting them from the relevant 10-K filings.

Our selection of firms covers a wide spectrum of different sectors, including 41 firms from clothing and apparel, 36 food companies (beverages and snacks), and 4 toy manufacturers. There are occasions where we exclude certain data points as they are not representative and can be considered to be outliers. For instance, some firms may have achieved a sudden and unprecedented increase in terms of their revenue or net income because they have merged with or acquired another firm. This is an anomaly to which our analysis is not well suited, partially due to the approach we use to obtain the trend, which will be explained further in the sections below. Thus, such data points are excluded from our analysis. 

MANAGEMENT , ECONOMICS AND HUMANITIES

\author{
26-28 July, 2019 \\ London, United Kingdom
}

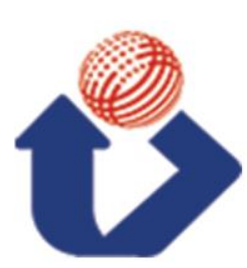

\begin{tabular}{|c|c|c|c|c|c|c|c|c|c|c|}
\hline 2 & A & B & c & D & E & $\mathrm{F}$ & G & $\mathrm{H}$ & I & $\mathrm{J}$ \\
\hline 1 & Company & Year & Revenue & Cost of Revenue & Gross Profit & Operating Expenses & Operating Income & Net Income & Number of Employees S & Sector \\
\hline 2 & Superior Group Of Companies, Inc. (SGC) & 2003 & $1.4 \mathrm{E}+08$ & 90334765 & 46991576 & 37491162 & 8803910 & 5703910 & 897 & Clothing \\
\hline 3 & Superior Group Of Companies, Inc. (SGC) & 2004 & $1.4 \mathrm{E}+08$ & 96279784 & 47287689 & 38524803 & 8138687 & 5378687 & $887 C$ & Clothing \\
\hline 4 & Superior Group Of Companies, Inc. (SGC) & 2005 & $1.3 \mathrm{E}+08$ & 93596828 & 39715523 & 37610557 & 1494185 & 1244185 & 722 & Clothing \\
\hline 5 & Superior Group Of Companies, Inc. (SGC) & 2006 & $1.2 \mathrm{E}+08$ & 84385588 & 39329185 & 33983449 & 3064710 & 2197567 & 696 & Clothing \\
\hline 6 & Superior Group Of Companies, Inc. (SGC) & 2007 & $1.2 \mathrm{E}+08$ & 80837592 & 39620299 & 33784794 & 5505831 & 2549328 & 623 & Clothing \\
\hline 7 & Superior Group Of Companies, Inc. (SGC) & 2008 & $1.2 \mathrm{E}+08$ & 83402581 & 40342620 & 34263750 & 4140333 & 2133773 & 525 & Clothing \\
\hline 8 & Superior Group Of Companies, Inc. (SGC) & 2009 & $1 \mathrm{E}+08$ & 69583043 & 33218878 & 30402389 & 2816489 & 1966882 & 564 & Clothing \\
\hline 9 & Superior Group Of Companies, Inc. (SGC) & 2010 & $1.1 \mathrm{E}+08$ & 68411000 & 37467000 & 31697000 & 5770000 & 3807000 & 626 & Clothing \\
\hline 10 & Superior Group Of Companies, Inc. (SGC) & 2011 & $1.1 \mathrm{E}+08$ & 72114000 & 40259000 & 34646000 & 5613000 & 4136000 & 640 & Clothing \\
\hline 11 & Superior Group Of Companies, Inc. (SGC) & 2012 & $1.2 \mathrm{E}+08$ & 79723000 & 39763000 & 35112000 & 4651000 & 3031000 & 685 & Clothing \\
\hline 12 & Superior Group Of Companies, Inc. (SGC) & 2013 & $1.5 \mathrm{E}+08$ & 98938000 & 52558000 & 43873000 & 8685000 & 5850000 & 967 & Clothing \\
\hline 13 & Superior Group Of Companies, Inc. (SGC) & 2014 & $2 E+08$ & 127512000 & 68737000 & 50724000 & 18013000 & 11349000 & 1043 & Clothing \\
\hline 14 & Superior Group Of Companies, Inc. (SGC) & 2015 & $2.1 \mathrm{E}+08$ & 138884000 & 71433000 & 52018000 & 19415000 & 13066000 & 1268 & Clothing \\
\hline 15 & Superior Group Of Companies, Inc. (SGC) & 2016 & $2.5 \mathrm{E}+08$ & 165614000 & 86982000 & 66396000 & 20586000 & 14638000 & 1620 & Clothing \\
\hline 16 & Superior Group Of Companies, Inc. (SGC) & 2017 & $2.7 \mathrm{E}+08$ & 170462000 & 96352000 & 70768000 & 25584000 & 15022000 & 2280 & Clothing \\
\hline 17 & Superior Group Of Companies, Inc. (SGC) & 2018 & $3.5 \mathrm{E}+08$ & 224653000 & 121697000 & 97095000 & 24602000 & 16975000 & 2877 & Clothing \\
\hline 18 & Deckers Outdoor Corp (DECK) & 2003 & $9.9 \mathrm{E}+07$ & 57577000 & 41530000 & 34954000 & 3348000 & 1620000 & 133 & Clothing \\
\hline 19 & Deckers Outdoor Corp (DECK) & 2004 & $1.2 \mathrm{E}+08$ & 69710000 & 51345000 & 32407000 & 19438000 & 9154000 & 134 & Clothing \\
\hline 20 & Deckers Outdoor Corp (DECK) & 2005 & $2.1 \mathrm{E}+08$ & 124354000 & 90433000 & 47971000 & 42462000 & 25539000 & 191 & Clothing \\
\hline 21 & Deckers Outdoor Corp (DECK) & 2006 & $2.7 E+08$ & 153238000 & 112522000 & 59254000 & 52268000 & 31845000 & 156 & Clothing \\
\hline 22 & Deckers Outdoor Corp (DECK) & 2007 & $3 E+08$ & 163692000 & 140731000 & 73989000 & 51442000 & 30609000 & 276 & Clothing \\
\hline 23 & Deckers Outdoor Corp (DECK) & 2008 & $4.5 \mathrm{E}+08$ & 241458000 & 207471000 & 101918000 & 105553000 & 66437000 & 370 & Clothing \\
\hline 24 & Deckers Outdoor Corp (DECK) & 2009 & $6.9 E+08$ & 384127000 & 305318000 & 152574000 & 116919000 & 73948000 & 640 & Clothing \\
\hline 25 & Deckers Outdoor Corp (DECK) & 2010 & $8.1 E+08$ & 442087000 & 371090000 & 189843000 & 181247000 & 116786000 & 1000 & Clothing \\
\hline 26 & Deckers Outdoor Corp (DECK) & 2011 & $1 \mathrm{E}+09$ & 498051000 & 502938000 & 253850000 & 249088000 & 160377000 & 1500 & Clothing \\
\hline 27 & Deckers Outdoor Corp (DECK) & 2012 & $1.4 \mathrm{E}+09$ & 698288000 & 678995000 & 394157000 & 284838000 & 201858000 & 1900 & Clothing \\
\hline 28 & Deckers Outdoor Corp (DECK) & 2013 & $1.4 \mathrm{E}+09$ & 782244000 & 632154000 & 445206000 & 186948000 & 129014000 & 2300 & Clothing \\
\hline
\end{tabular}

We have edited and recorded all the data in an Excel spreadsheet in the panel form. We then carry out our operations with all these numbers in Stata.

Our approach is to see the changes in the growth rates of revenue and net income of all the firms during these three stages. By analysing the relationship between these changes and the market power, we can then deduce how market power affects the performance of the firms given that they experience the same recession. This in turn addresses the main question of the paper directly.

Firstly, we divide the companies into two categories: price makes and price takers, based on their respective value of the Lerner Index, whose definition we suitably adapt for our purposes. As the Lerner Index is calculated by the price of the goods minus the marginal cost and then divided by the price, $(\mathrm{P}-\mathrm{MC}) / \mathrm{P}$, we decide to use the value of net income as the numerator, and the revenue as the denominator of the equation. This is due to the unavailability of the data on the marginal cost of each firm, given that it is one of its top business secrets. To justify this simplification, we assume that the marginal cost is constant, which may not always be true in the real world. However, such a measure remains a good proxy of the firm's market power.

There is one key difference between the "original" Lerner Index and our version of it, which is that the former only ranges from 0 to 1 . However, in our study, we decide to take into consideration the empirical context which that the firm can actually make a loss (net income is negative). Therefore, our Net Lerner Index can become negative. The directional interpretation is howeveer the same, which is that a larger value means the company possesses more market power.

With this unit value, we then define the average value of the market power of each firm from 2003 to 2018 by calculating the mean value of our Net Lerner Index over time, which we denote as the 


\title{
$9^{\text {th }}$ INTERNATIONAL CONFERENCE ON MANAGEMENT , ECONOMICS AND HUMANITIES
}

\author{
26-28 July, 2019 \\ London, United Kingdom
}

Average Net Lerner Index. This gives us a good estimation of the general market power of each individual firm. By again taking the mean value of the Average Net Lerner Index, this time over all the firms, we define a new variable called the Global Average Net Lerner Index to represent the average market power of in the industry. Finally, we define the dummy variable, Price Maker, which is 1 , if the Average Net Lerner Index is higher than Global Average Net Lerner Index and 0 otherwise. We believe this is a more reasonable approach as compared to setting a specific threshold value of the index to define the dummy variable, because we are making being a price maker and a price taker a relative term, thus avoiding the case where every firm becomes a price maker if an inappropriate parameter is set.

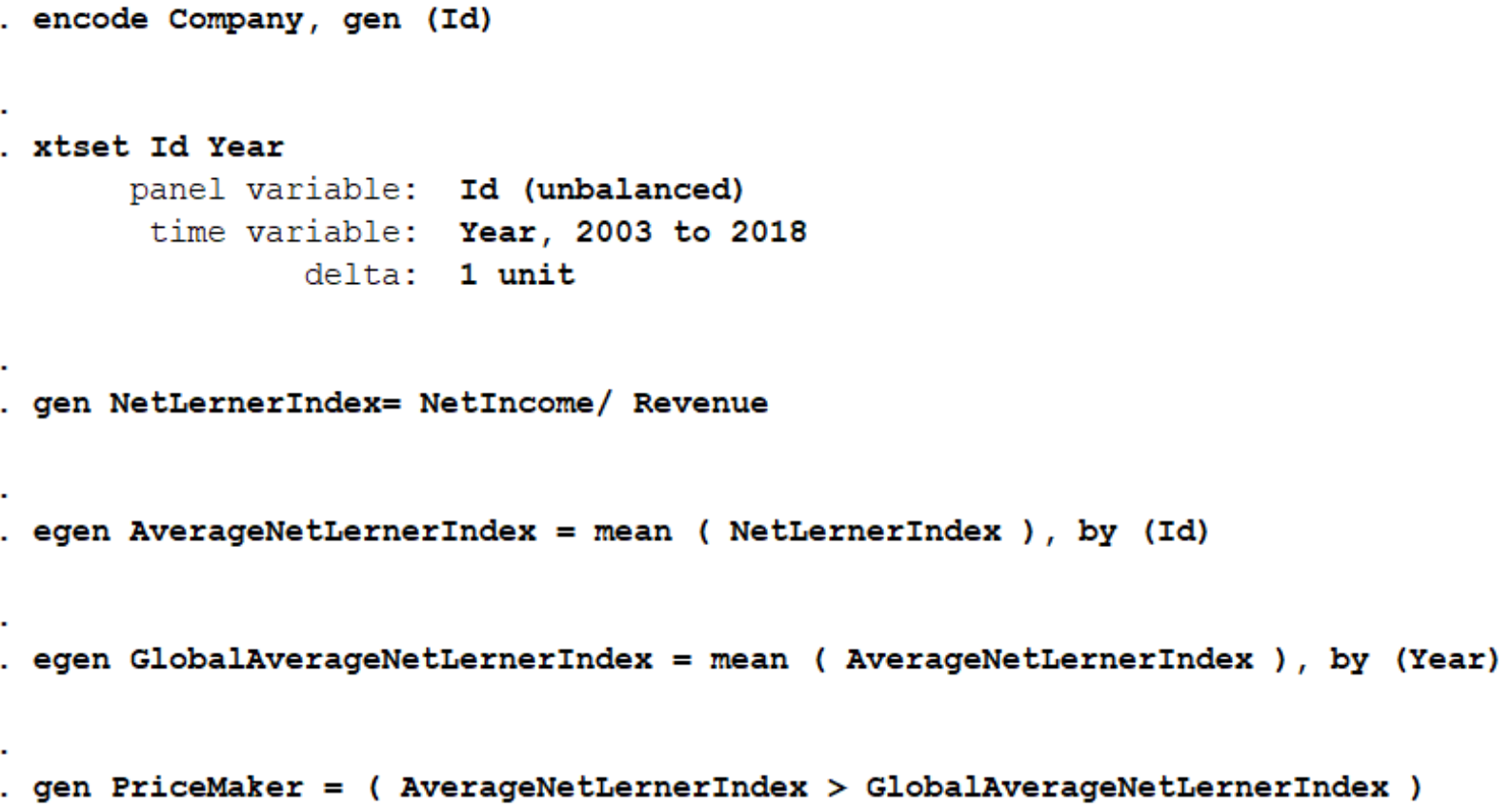

After defining market power, we move on to explore the behaviour of Revenue and Net Income in the three relevant time periods. In this paper, we define the 'before' stage to be from the year 2003 to 2007, the 'during' stage from 2008 to 2010, and the 'after' stage from 2011 to 2015 . One potential confusion here is the time period for which the recession happens. Although all the papers mentioned beforehand define the recession period to be 2007-2009, we believe that in terms of the performance of the firms, it is better to look at data from 2008 to 2010. Since the recession started in late 2007, the performances of firms are not sufficiently impacted or even not felt by some of the firms in 2007. And even though the recession ended in 2009, firms still struggle to recover in 2010, which makes 2010 an appropriate candidate for the 'during' stage.

Next, we decide to explore the changes in Net Income of price makers and price takers. For all the firms, we first find the mean value of their Net Income in all three stages, which are denoted as Average Net 


\section{$9^{\text {th }}$ INTERNATIONAL CONFERENCE ON MANAGEMENT , ECONOMICS AND HUMANITIES \\ 26-28 July, 2019 \\ London, United Kingdom}

Income Before, During, and After. Then we find the change of the net income for each firm, by subtracting the average value of net income of the previous stage. This way, only two values for each firm are obtained, which are the Change in Average Net Income BD (During - Before) and Change of Average Net Income DA (After - During).

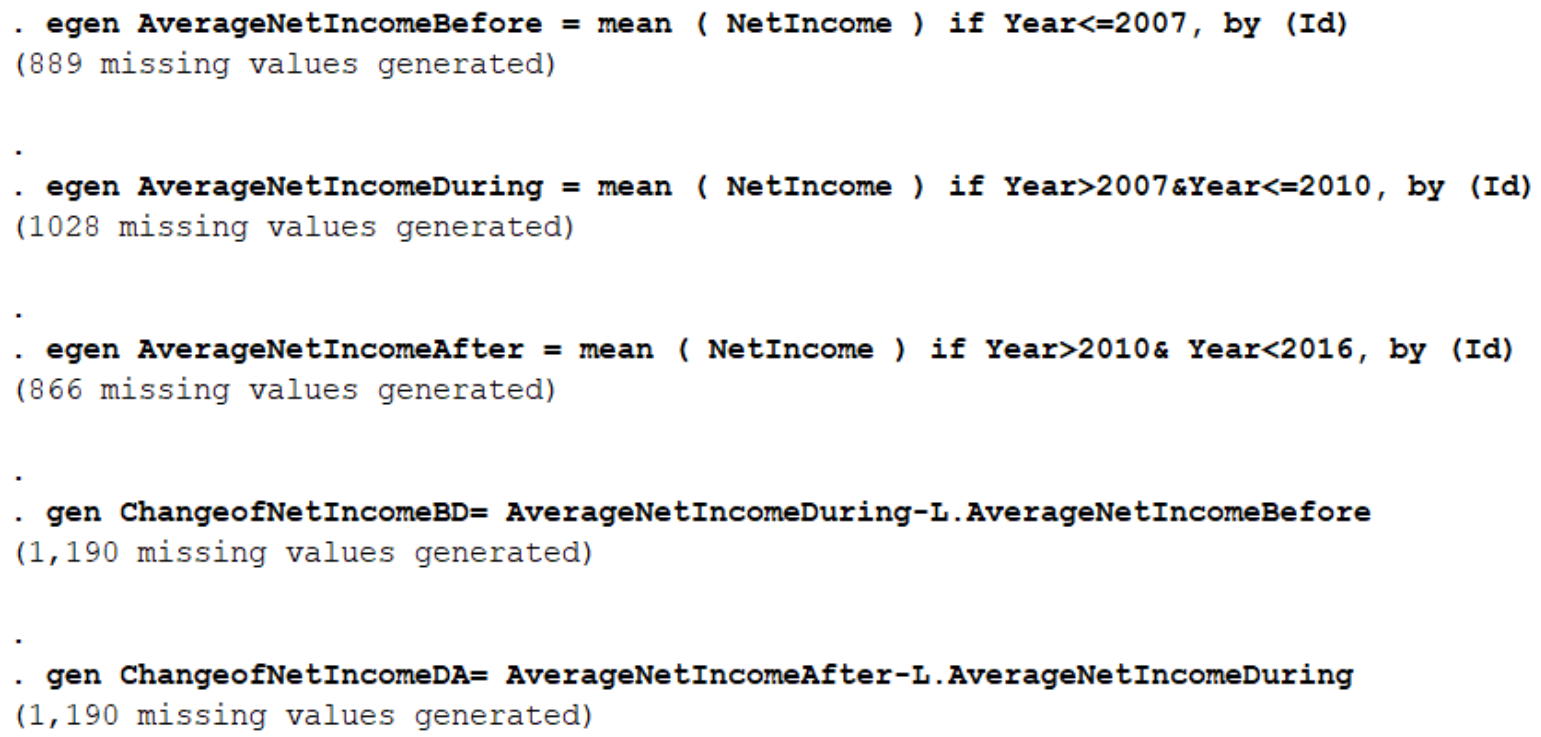

Although these two values give us the actual change of net income during the recession, they are largely affected by the size of the firms, with larger firms having a larger change in their earnings but may not necessarily indicate that the bigger firms perform worse than small firms. Therefore, we generate two more indicators which express this change in percentage terms. For the change of net income BD, we generate the Percentage Change in Average Net Income BD, which is calculated by Change in Average Net Income BD divided by the absolute value Average Net Income Before. The absolute value is to prevent any miscalculations and misinterpretations of the data if the two values of different stages have different signs. Likewise, a new variable Percentage Change in Average Net Income DA is created.

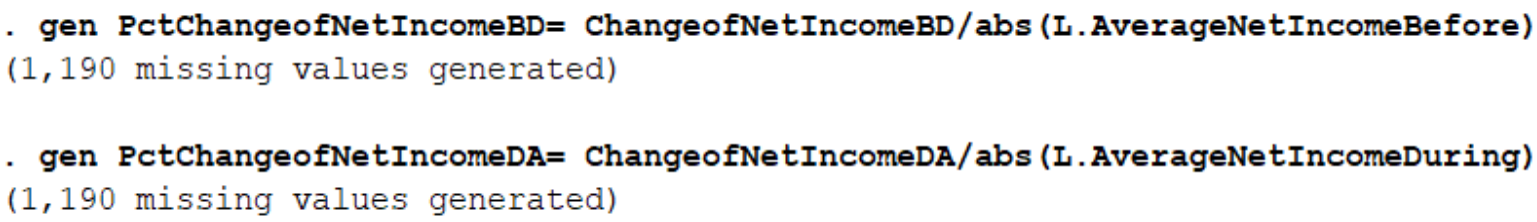

We then repeat the same process for Revenue, generating similar indicators: Percentage Change of Average Revenue BD and Percentage Change of Average Revenue DA. Note here we did not use the absolute value when generating the percentage as the Revenue are all positive values. 


\section{$9^{\text {th }}$ INTERNATIONAL CONFERENCE ON MANAGEMENT , ECONOMICS AND HUMANITIES

- egen AverageRevenueBefore = mean ( Revenue ) if Year $<=2007$, by (Id)

(889 missing values generated)

- egen AverageRevenueDuring = mean ( Revenue) if Year $>2007$ \& Year $<=2010$, by (Id)

(1028 missing values generated)

- egen AverageRevenueAfter = mean ( Revenue) if Year $>2010$ \&Year<2016, by (Id)

(866 missing values generated)

- gen ChangeofRevenueBD= AverageRevenueDuring-L.AverageRevenueBefore

$(1,190$ missing values generated)

- gen ChangeofRevenueDA= AverageRevenueAfter-L.AverageRevenueDuring

(1,190 missing values generated)

\section{- gen PctChangeofRevenueBD= ChangeofRevenueBD/L.AverageRevenueBefore \\ (1,190 missing values generated) \\ - gen PctChangeofRevenueDA= ChangeofRevenueDA/I.AverageRevenueDuring \\ (1,190 missing values generated)}

After obtaining all the indicators we need, we start to plot basic graphs to see the general trend in the difference of firms' performances between the price makers and the price takers. Firstly, we use the box plot for every indicator to check for the outliers and try to find what causes them to be so special and before deciding whether we should exclude them. After that, we run linear regressions of the indicators with respect to the Price Maker dummy variable to see whether we can obtain a statistically significant relationship at $95 \%$ confidence interval. Finally, we interpret the data and see the magnitude of the impact of market power on the performance of firms in all three time periods.

We begin with the change in the actual amount of the net income between different stages, for which we box plot the value of Change in Average Net Income BD against the dummy variable, Price Maker. 


\section{$9^{\text {th }}$ INTERNATIONAL CONFERENCE ON MANAGEMENT , ECONOMICS AND HUMANITIES}

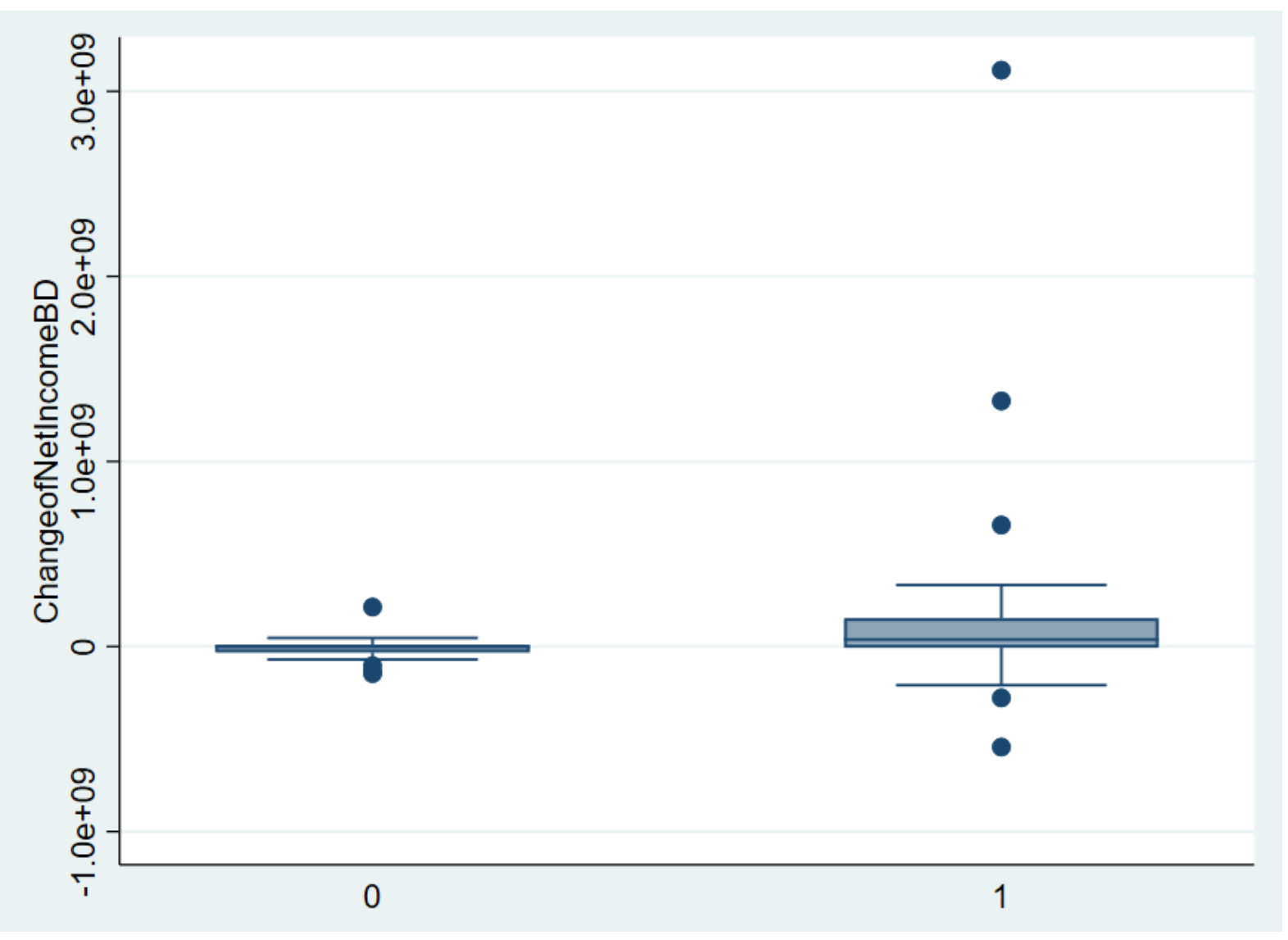

The graph contains little information as the scale is distorted due to the scale of net incomes being larger for price makers. However, the first hypothesis that suggests itself is that both price makers and price takers have the range of change in net income close to 0 , with a relatively higher positive value obtained by the price makers. This means that the average net income during the recession is around the same for most of the price takers and slightly increases for price makers. This is in line with our expectation whereby the recession impacts the growth of firms. In this case, although the points are spread out, we did not exclude any point as it is expected that the big firms will have a much higher change in their net incomes.

Next, we move on to running a linear regression to quantify this trend. Firstly, we regress the Change of Average Net Income BD against Price Maker dummy as well as against price maker and the Number of Employees together. This is to see whether the firm's physical size affects the results of the regression. 


\section{$9^{\text {th }}$ INTERNATIONAL CONFERENCE ON MANAGEMENT , ECONOMICS AND HUMANITIES}

26-28 July, 2019

London, United Kingdom

\begin{tabular}{|c|c|c|c|c|c|c|}
\hline Source & SS & df & MS & \multirow{2}{*}{$\begin{array}{l}\text { Number of obs } \\
\mathrm{F}(1,79) \\
\text { Prob > F }\end{array}$} & $=$ & 81 \\
\hline Model & $4.5288 e+17$ & 1 & $4.5288 e+17$ & & $=$ & 0.0901 \\
\hline Residual & 1. $2153 e+19$ & 79 & $1.5384 \mathrm{e}+17$ & $\mathrm{R}$-squared & $=$ & 0.0359 \\
\hline Total & $1.2606 \mathrm{e}+19$ & 80 & $1.5758 \mathrm{e}+17$ & $\begin{array}{l}\text { Adj R-squared } \\
\text { Root MSE }\end{array}$ & $=$ & $\begin{array}{l}0.0237 \\
3.9 e+08\end{array}$ \\
\hline ChangeofNe $\sim \mathrm{D}$ & Coef. & Std. Err. & $t$ & [95\% Con & f. & Interval] \\
\hline Pricemaker & $1.52 \mathrm{e}+08$ & $8.87 e+07$ & 1.72 & $-2.44 e+07$ & & $3.29 e+08$ \\
\hline _cons & -9006039 & $6.83 e+07$ & -0.13 & $-1.45 e+08$ & & $1.27 e+08$ \\
\hline
\end{tabular}

- regress ChangeofNetIncomeBD PriceMaker NumberofEmployees

\begin{tabular}{|c|c|c|c|c|c|c|}
\hline Source & SS & df & MS & Number of obs & $=$ & 81 \\
\hline Model & 2. $9605 e+18$ & 2 & 1. $4803 e+18$ & Prob & $=$ & 0.0000 \\
\hline Residual & $9.6455 e+18$ & 78 & 1. $2366 \mathrm{e}+17$ & R-squared & $=$ & 0.2349 \\
\hline & & & & Adj R-squared & $=$ & 0.2152 \\
\hline Total & 1. $2606 \mathrm{e}+19$ & 80 & 1. $5758 \mathrm{e}+17$ & Root MSE & $=$ & $3.5 e+08$ \\
\hline
\end{tabular}

\begin{tabular}{|c|c|c|c|c|c|c|}
\hline ChangeofNet Inco D & Coef. & Std. Err. & $t$ & $P>|t|$ & {$[95 \%$ Conf. } & Interval] \\
\hline PriceMaker & $3.52 e+07$ & $8.37 e+07$ & 0.42 & 0.675 & $-1.31 e+08$ & $2.02 e+08$ \\
\hline NumberofEmployees & 5950.009 & 1321.287 & 4.50 & 0.000 & 3319.529 & 8580.489 \\
\hline _cons & $-3.89 e+07$ & $6.16 e+07$ & -0.63 & 0.529 & $-1.62 e+08$ & $8.37 e+07$ \\
\hline
\end{tabular}

Unfortunately, in both cases, the relationship between Change of Average Net Income BD and Price Maker is not statistically significant at the $95 \%$ confidence interval. Although the coefficient seems to suggest that the Net Income will increase more during the recession for price makers in both cases, we cannot conclude the relationship is meaningful. However, the regression does suggest that firms with larger size will have a higher increase in net income.

Besides the dummy variable, we also run the regression against the Average Net Lerner Index of each individual firm, hoping to see a more specific trend between Net Income and market power. Again, we have also tested the effect of the size of the firm on this relationship. 


\section{$9^{\text {th }}$ INTERNATIONAL CONFERENCE ON MANAGEMENT , ECONOMICS AND HUMANITIES}

26-28 July, 2019

London, United Kingdom

regress ChangeofNetIncomeBD AverageNetLernerIndex

\begin{tabular}{|c|c|c|c|c|c|c|}
\hline Source & SS & df & MS & Number of obs & $=$ & 81 \\
\hline Model & $9.2644 \mathrm{e}+17$ & 1 & $9.2644 e+17$ & Prob $>\mathrm{F}$ & $=$ & 0.0144 \\
\hline Residual & $1.1680 \mathrm{e}+19$ & 79 & 1. $4784 \mathrm{e}+17$ & $\mathrm{R}$-squared & $=$ & 0.0735 \\
\hline Total & $1.2606 \mathrm{e}+19$ & 80 & $1.5758 e+17$ & $\begin{array}{l}\text { Ad] R-squared } \\
\text { Root MSE }\end{array}$ & $\begin{array}{l}= \\
=\end{array}$ & $3.8 e+08$ \\
\hline
\end{tabular}

\begin{tabular}{r|rrrrrr}
\hline ChangeofNetIncomeBD & Coef. & Std. Err. & $t$ & P $>|t|$ & [95\% Conf. Interval] \\
\hline AverageNetLernerIndex & $1.21 e+09$ & $4.85 e+08$ & 2.50 & 0.014 & $2.49 e+08$ & $2.18 e+09$ \\
_Cons & $3.03 e+07$ & $4.73 e+07$ & 0.64 & 0.524 & $-6.39 e+07$ & $1.24 e+08$ \\
\hline
\end{tabular}

regress ChangeofNetIncomeBD AverageNetLernerIndex NumberofEmployees

\begin{tabular}{|c|c|c|c|c|c|c|}
\hline Source & SS & df & MS & Number of obs & $=$ & 81 \\
\hline Model & $3.2724 e+18$ & 2 & 1. $6362 \mathrm{e}+18$ & Prob > F & $=$ & 0.0000 \\
\hline Residual & $9.3336 \mathrm{e}+18$ & 78 & $1.1966 \mathrm{e}+17$ & R-squared & $=$ & 0.2596 \\
\hline Total & 1. $2606 \mathrm{e}+19$ & 80 & $1.5758 \mathrm{e}+17$ & $\begin{array}{l}\text { Adj R-squared } \\
\text { Root MSE }\end{array}$ & $\begin{array}{l}= \\
=\end{array}$ & $\begin{array}{l}0.2406 \\
3.5 e+08\end{array}$ \\
\hline
\end{tabular}

\begin{tabular}{r|rrrrrr}
\hline ChangeofNetIncomeBD & Coef. & Std. Err. & $t$ & P $>|t|$ & [95\% Conf. Interval] \\
\hline AveragenetLernerIndex & $\mathbf{7 . 4 9 e + 0 8}$ & $\mathbf{4 . 4 9 e + 0 8}$ & 1.67 & 0.099 & $\mathbf{- 1 . 4 4 e + 0 8}$ & $1.64 \mathrm{e}+09$ \\
NumberofEmployees & $\mathbf{5 6 2 6 . 3 2 3}$ & 1270.691 & $\mathbf{4 . 4 3}$ & 0.000 & $\mathbf{3 0 9 6 . 5 7 1}$ & $\mathbf{8 1 5 6 . 0 7 5}$ \\
_Cons & $-4.41 \mathrm{e}+07$ & $\mathbf{4 . 5 8 e + 0 7}$ & -0.96 & 0.338 & $\mathbf{- 1 . 3 5 e + 0 8}$ & $\mathbf{4 . 7 0 e + 0 7}$ \\
\hline
\end{tabular}

In the first case, the relationship between Net Income and Average Net Lerner Index is statistically meaningful. The higher the index is, or the more market power the firms has, the higher the increase in the Net Income during the recession. This suggests that the price makers will suffer less from the recession in terms of their profits. Besides, we have also obtained another statistically meaningful value for the impact of the size of the firms, indicating the same trend as the previous regression. In addition, upon adding the number of employees into the regression, the relationship between the change of net income and market power becomes less meaningful. This raises the question of how the size of firms and market power are related to each other. Therefore, we run the regression between these two variables. 


\section{$9^{\text {th }}$ INTERNATIONAL CONFERENCE ON MANAGEMENT , ECONOMICS AND HUMANITIES}
26-28 July, 2019
London, United Kingdom

- regress NumberofEmployees AverageNetLernerIndex

\begin{tabular}{|c|c|c|c|c|c|c|}
\hline Source & SS & $\mathrm{df}$ & MS & Number of obs & $=$ & 1,268 \\
\hline Model & 8. $6695 e+10$ & 1 & $8.6695 e+10$ & Prob $>\mathrm{F}$ & $=$ & 0.0000 \\
\hline Residual & $1.5228 e+12$ & 1,266 & $1.2028 e+09$ & R-squared & $=$ & 0.0539 \\
\hline Total & 1. $6095 \mathrm{e}+12$ & 1,267 & $1.2703 e+09$ & Root MSE & $\begin{array}{l}= \\
=\end{array}$ & $\begin{array}{r}.0531 \\
34682\end{array}$ \\
\hline
\end{tabular}

\begin{tabular}{r|rrrrrr}
\hline NumberofEmployees & Coef. & Std. Err. & $t$ & P $>|t|$ & [95\% Conf. Interval] \\
\hline AveragenetLernerIndex & 102261.8 & 12045.34 & $\mathbf{8 . 4 9}$ & 0.000 & $\mathbf{7 8 6 3 0 . 8}$ & 125892.9 \\
Cons & 14212 & 1114.448 & 12.75 & 0.000 & 12025.63 & 16398.37 \\
\hline
\end{tabular}

As shown, the two variables are linearly related with a positive gradient. The higher the market power is, the more employees the firm is likely to have. While the direction of causality is unclear, the high positive correlation leads to multicollinearity, which reduces the explanatory power of the market power indicator.All the above tests are based on the actual change of the Net Income of the firms during the recession. Next, we move on to the percentage change of the Net Income of the firms.

Basically, we follow the same list of the tests, only changing the variable Change of Average Net Income BD to Percentage Change of Average Net Income BD. Once again we box plot all the data points against the dummy variable Price Maker, just to check whether there is any exceptions or anomalous points to be excluded.

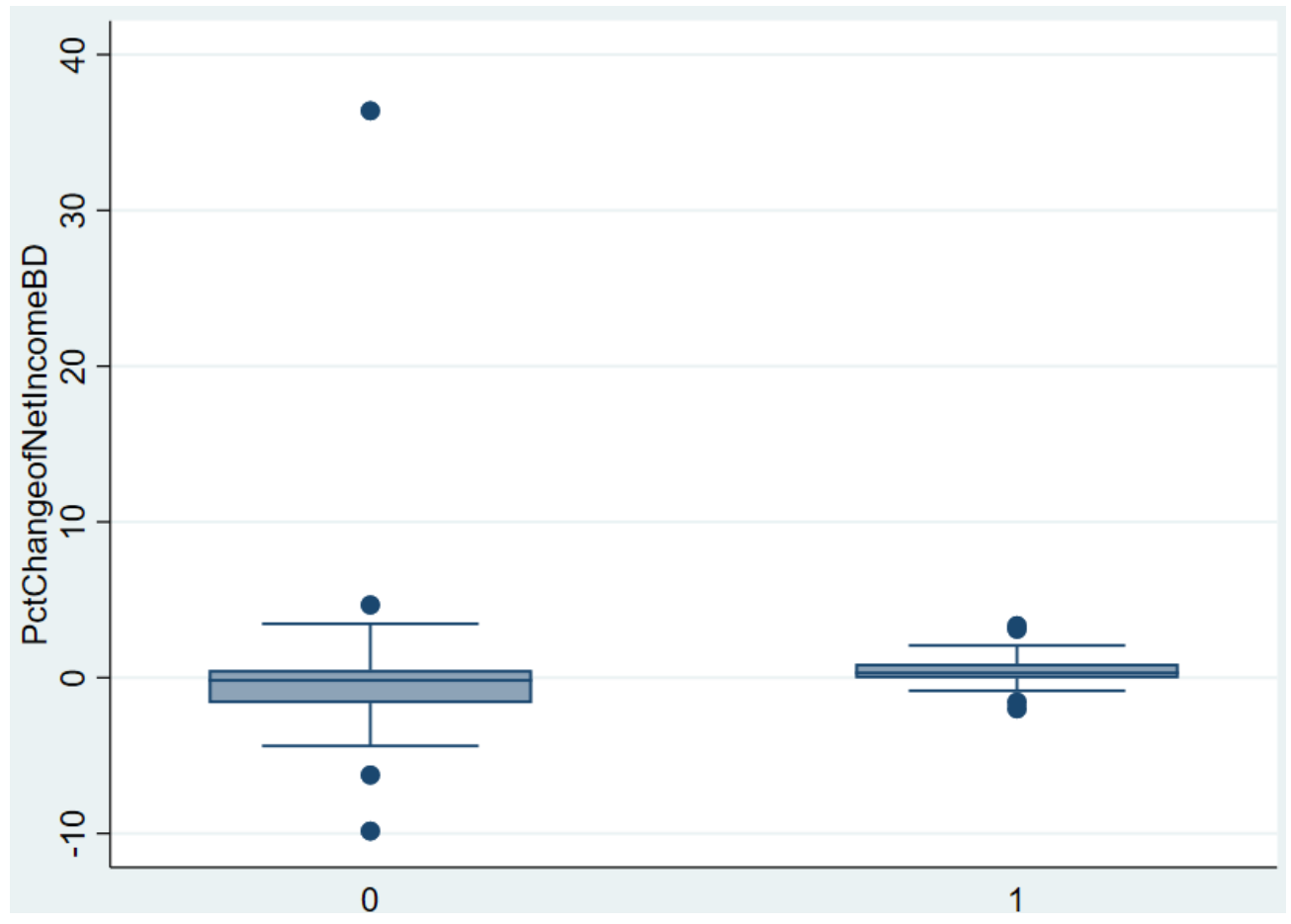




\title{
$9^{\text {th }}$ INTERNATIONAL CONFERENCE ON MANAGEMENT , ECONOMICS AND HUMANITIES
}

\author{
26-28 July, 2019 \\ London, United Kingdom
}

One required clarification is that we actually leave the the percentage change as a decimal (i.e. it is not multiplied by 100). Thus, it is clear that one of the data points for price takers deviates from the general range of other values to a large extent, with the net income during the recession being more than 35 times higher than before the recession. This means the firm did exceedingly well during the recession, which seems unlikely. The reason of this is that the firm, Rave Restaurant Group, Inc. (RAVE), has been going through a tough period even before the recession hit, leading to a very low and in fact, slightly negative Average Net Income Before. In this case, we have decided to drop this particular data point in our analysis as it is not representative of the overall performance of all the firms.

Again, we use the dummy variable to test for the relationship between percentage change of net income and market power, together with the size of the firm indicated by the number of employees. Here to exclude the exception, we add in another side command on the linear regression, which is essentially run the regression only with data that has a value below 30 .

\begin{tabular}{|c|c|c|c|c|c|c|}
\hline Source & SS & $\mathrm{df}$ & MS & Number of obs & $=$ & 80 \\
\hline Model & 31.2412529 & 1 & 31.2412529 & Prob > F & $=$ & 0.0034 \\
\hline Residual & 266.772611 & 78 & 3.42016168 & R-squared & $=$ & 0.1048 \\
\hline & & & & Adj R-squared & $=$ & 0.0934 \\
\hline Total & 298.013864 & 79 & 3.77232739 & Root MSE & $=$ & 1.8494 \\
\hline
\end{tabular}

\begin{tabular}{r|rrrrrr}
\hline PctChangeo D & Coef. & Std. Err. & $t$ & P $>|t|$ & [95\% Conf. Interval] \\
\hline PriceMaker & 1.275597 & .4220586 & 3.02 & 0.003 & .4353433 & 2.115851 \\
_cons & -.8396316 & .3269251 & -2.57 & 0.012 & -1.49049 & -.1887737 \\
\hline
\end{tabular}

\begin{tabular}{|c|c|c|c|c|c|c|}
\hline Source & SS & df & MS & Number of obs & $=$ & 80 \\
\hline Model & 31.7397649 & 2 & 15.8698825 & Prob > F & $=$ & 0.0131 \\
\hline Residual & 266.274099 & 77 & 3.45810518 & R-squared & $=$ & 0.1065 \\
\hline Total & 298.013864 & 79 & 3.77232739 & Root MSE & $=$ & 1.8596 \\
\hline
\end{tabular}

\begin{tabular}{r|rrrrrr}
\hline PctChangeofNetI D & Coef. & Std. Err. & $t$ & P > t l & [95\% Conf. Interval] \\
\hline PriceMaker & 1.327367 & .4457592 & 2.98 & 0.004 & .4397473 & 2.214987 \\
NumberofEmployees & $-2.65 e-06$ & $6.99 e-06$ & -0.38 & 0.705 & -.0000166 & .0000113 \\
Cons & -.8258824 & .3307222 & -2.50 & 0.015 & -1.484434 & -.1673304 \\
\hline
\end{tabular}

As shown, in both cases, the relationship between market power and percentage change of net income is statistically significant. It is according to our expectations that the price makers will suffer less in terms of the loss in their earnings. Taking into account the constant, an average price taker is likely to lose more than $80 \%$ of its net income, whereas an average price maker is able to increase its net income by around 


\section{$9^{\text {th }}$ INTERNATIONAL CONFERENCE ON MANAGEMENT , ECONOMICS AND HUMANITIES}

26-28 July, 2019

$40 \%$ to $50 \%$. However, when it comes to the size of the firm, it seems to be the case that the size of the firm does not impact the percentage change of the net income.

We also run the regression with the Average Net Lerner Index.

- regress PctChangeofNetIncomeBD AverageNetLernerIndex if abs ( PctChangeofNetIncomeBD) $<3$ $>0$

\begin{tabular}{|c|c|c|c|c|c|c|}
\hline Source & SS & $d f$ & MS & Number of obs & $=$ & \\
\hline Model & 57.3753762 & 1 & 57.3753762 & Prob > F & $=$ & 0.0000 \\
\hline Residual & 240.638488 & 78 & 3.08510882 & R-squared & $=$ & 0.1925 \\
\hline Total & 298.013864 & 79 & 3.77232739 & $\begin{array}{l}\text { Adj R-squared } \\
\text { Root MSE }\end{array}$ & $\begin{array}{l}= \\
=\end{array}$ & $\begin{array}{l}0.1822 \\
1.7564\end{array}$ \\
\hline
\end{tabular}

\begin{tabular}{r|rrrrrr}
\hline PctChangeofNetIncom D & Coef. & Std. Err. & $t$ & P $>|t|$ & [95\% Conf. Interval] \\
\hline AveragenetLernerIndex & $\mathbf{9 . 5 9 1 3 1 6}$ & $\mathbf{2 . 2 2 4 0 8 1}$ & $\mathbf{4 . 3 1}$ & 0.000 & $\mathbf{5 . 1 6 3 5 1}$ & 14.01912 \\
Cons & -.4848102 & .2182347 & -2.22 & 0.029 & -.9192821 & -.0503383 \\
\hline
\end{tabular}

- regress PctChangeofNetIncomeBD AverageNetLernerIndex NumberofEmployees if abs( PctChang

$>$ eofNetIncomeBD ) $<30$

\begin{tabular}{|c|c|c|c|c|c|c|}
\hline Source & SS & df & MS & Number of obs & $=$ & \\
\hline Model & 57.8969386 & 2 & 28.9484693 & Prob > F & $=$ & 0.0002 \\
\hline Residual & 240.116925 & 77 & 3.11840163 & R-squared & $=$ & 0.1943 \\
\hline & & & & Adj R-squared & $=$ & 0.1733 \\
\hline Total & 298.013864 & 79 & 3.77232739 & Root MSE & $=$ & 1.7659 \\
\hline
\end{tabular}

\begin{tabular}{r|rrrrrr}
\hline PctChangeofNetIncom D & Coef. & Std. Err. & $t$ & P $>|t|$ & [95\% Conf. Interval] \\
\hline AveragenetLernerIndex & 9.807202 & 2.297516 & 4.27 & 0.000 & $\mathbf{5 . 2 3 2 2 6 4}$ & 14.38214 \\
NumberofEmployees & $-2.65 e-06$ & $6.49 e-06$ & -0.41 & 0.684 & -.0000156 & .0000103 \\
Cons & -.4492127 & .2360441 & -1.90 & 0.061 & -.9192364 & .0208111
\end{tabular}

Again, the results are statistically significant and suggest that the firms with more market power are likely to make more profit during the recession, as compared to firms with low or zero market power who are likely to make a loss. In addition, the size of the firms may really have no effect on the percentage change of net income, as suggested by the two similar sets of regression results. It can be noted that the value here differs from the previous ones when we run the regression with the dummy variable, which is again because of the negative Net Lerner Index of some firms, making the gradient of the graph steeper than expected. 


\title{
$9^{\text {th }}$ INTERNATIONAL CONFERENCE ON MANAGEMENT , ECONOMICS AND HUMANITIES
}

\author{
26-28 July, 2019 \\ London, United Kingdom
}

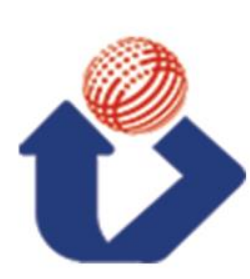

So far we have completed the analysis on the change in net income during the recession. Overall, from the results we have obtained so far, it appears to be clear that the more market power the firm possesses, the less it is affected during a recession, whether in terms of the actual amount of net income or the percentage change. However, the size of the firm only impacts the actual amount of the change in net income, with larger firms having larger changes in their net income. When it comes to the percentage change of net income, the size has minimal effect.

For the BD stage (before and during the recession), we also complete the set of analysis on the change in revenue, rather than net income, with the identical command, and the results will be shown in Appendix A below. From the results, it is clear that the market power has little impact on the change of revenue during the recession, regardless of whether it is the absolute change or the percentage change. However, despite the result not being statistically significant, it does seem that firms with more market power will experience a larger change in revenue. Moreover, the results on the percentage change of revenue have indicated that even though the firm may have little or zero market power, its revenue still likely to increase during the recession, with the positive value of the constant being statistically significant. This suggests that most of the firms, price makers and price takers, will have a higher revenue during the recession, with price makers experiencing a larger increase.

As mentioned, we are also interested in the effect of market power or size of firms has on the recovery after the recession. We choose the time period of 'after' stage to be from 2011 to 2015, using the performance of firms from 5 years after the recession. Therefore, we are using another set of variables, denoted DA, which measures the difference in net income or revenue between the 'during' and 'after' stage. Once again, we present the analysis here and the full set of results are listed in Appendix B and C.

For the absolute change in net income after the recession, we have positive results indicating that both price makers and price takers are likely to improve their performance, with most of the price makers having a larger increase in their net income than price takers. As for the size of the firms, although the results are not statistically significant, we can still deduce that larger firms tend to have a larger increase of net income.

When it comes to the percentage change in net income, we have one anomalous data, Stage Stores Inc (SSI), who suffered a tough year during the recession, incurring a huge loss that dragged the average net income during recession down to nearly 0 . This causes the percentage change of net income after the recession of this firm to be extremely high. Thus, it has to be excluded from our regression, as it is not representative of the behaviour of all the firms. With that, we obtain significant results suggesting that both price makers and price takers will have a higher growth rate after the recession. However, it seems that the increase in growth rate is independent of both market power and size of the firms, with results on both variables not statistically significant.

For the absolute change in revenue, we have obtained positive results showing that both price makers and price takers will experience an increase in their revenue and the price makers will likely to enjoy a higher increase. Besides, the size of the firms does matter in this case. The larger the firm is, the higher the increase in revenue.

As for the percentage increase in revenue, despite the lack of significant results, there is an almost statistically significant result for the price maker dummy. This indicates that the price makers are likely to enjoy a higher percentage increase in their revenue as compared to the price takers. Again, similar to the 


\title{
$9^{\text {th }}$ INTERNATIONAL CONFERENCE ON MANAGEMENT , ECONOMICS AND HUMANITIES
}

\author{
26-28 July, 2019 \\ London, United Kingdom
}

percentage change of net income, the size of the firms does not play a significant role in the percentage increase in revenue after the recession.

\section{Conclusion}

To conclude, during a recession, in terms of net income, price takers are likely to make a loss while the price makers are likely to experience an increase in their earnings. Furthermore, even though the revenue of all firms is likely to rise, price makers still enjoy a larger increase in their revenue, despite the impact of market power on revenue being not statistically significant at the $95 \%$ confidence level. However, after the recession, when firms start to recover, although price makers have a larger increase in their net income, the market power has little effect on the percentage increase in net income. As for the revenue, the trend is more or less similar to the previous stage, with price makers having a larger increase in both the absolute amount and the percentage measures. Last but not least, one common observation across all the results is that the size of the firm, or the number of employees, only affects the change in the absolute values of net income or revenue but not the percentage change.

This seems to prove that a number of theories presented in the introduction correct, including the ones about price elasticity, unemployment, and the size of firms. These theories essentially predict that the price makers will suffer less during a recession. On the contrary, the other theories, such as simpler business structure bringing more advantage to small firms, seem to be unjustifiable based on our study.

Of course, our conclusion may and should only apply to the manufacturing sector of the US economy, as all our sample data come from this specific part of the economy. Besides, we have to make a concession that our analysis might be limited due to various reasons. For instance, we only include 81 firms in our dataset, which can be considered a small sample and hence it might not be able to represent the entire manufacturing sector. Other than this, the way we extend the range of Lerner Index to fit for the purpose of our study may also give rise to inaccurate results and potential misinterpretations of the data. In addition, although positive results are generated, the choice of time period of the three stages might not be the most suitable one. We may also need to consider more factors to be kept constant, such as the extent of the firm is in debt at the start of the recession, and failure to do so can in turn give us more biased and les accurate results. Therefore, more work should be done to find out other potential trends on how market power affects the performance of firms during and after the recession in other sectors and in other parts of the world to eventually have a more holistic answer to the main question of this paper.

\section{References}

Posner, R. A., \& Landes, W. M. (1980). Market Power in Antitrust Cases. Faculty Scholarship.

Crawford, C., Jin, W., \& Simpson, H. (2013). Productivity, Investment and Profits during the Great Recession: Evidence from UK Firms and Workers*. Fiscal Studies,34(2), 153-177. 


\section{$9^{\text {th }}$ INTERNATIONAL CONFERENCE ON MANAGEMENT , ECONOMICS AND HUMANITIES \\ 26-28 July, 2019

Fort, T., Haltiwanger, J., Jarmin, R., \& Miranda, J. (2013). How Firms Respond to Business Cycles: The Role of Firm Age and Firm Size.

Duygan-Bump, B., Levkov, A., \& Montoriol-Garriga, J. (2014). Financing Constraints and Unemployment: Evidence from the Great Recession. SSRN Electronic Journal.

Mariuzzo, F., Walsh, P. P., \& Whelan, C. (2003). Firm Size and Market Power in Carbonated Soft Drinks. Review of Industrial Organization,23(3/4), 283-299.

Prasetyantoko, A., \& Parmono, R. (2009). DoeS FirM Size Matter? An Empirical Study of Firm Performance in Indonesia. Journal ManaJeMen Bisnis, Vol. 2, no. 2, 87-97.

Barker, M. M. (2011). Manufacturing employment hard hit during the 2007-09 recession. The 2007-09 Recession: Manufacturing.

Coulter, S. (2016). The UK labour market and the 'great recession'. Unemployment, Internal Devaluation and Labour Market Deregulation in Europe, 197-227.

\section{Appendix A}

Change in revenue in BD stage 


\section{$9^{\text {th }}$ INTERNATIONAL CONFERENCE ON MANAGEMENT , ECONOMICS AND HUMANITIES}

26-28 July, 2019

London, United Kingdom

regress ChangeofRevenueBD PriceMaker

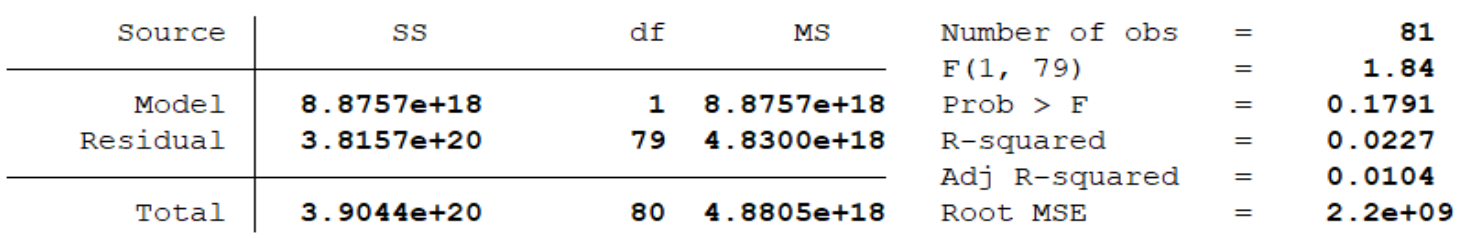

\begin{tabular}{|c|c|c|c|c|c|c|}
\hline ChangeofRe $\sim \mathrm{D}$ & coef. & Std. Err. & $t$ & $P>|t|$ & [95\% Conf. & Interval] \\
\hline Pricemaker & $6.74 e+08$ & $4.97 e+08$ & 1.36 & 0.179 & $-3.16 e+08$ & $1.66 \mathrm{e}+09$ \\
\hline$-^{\text {cons }}$ & $4.18 e+08$ & $3.83 e+08$ & 1.09 & 0.278 & $-3.43 e+08$ & $1.18 \mathrm{e}+09$ \\
\hline
\end{tabular}

- regress ChangeofRevenueBD PriceMaker NumberofEmployees

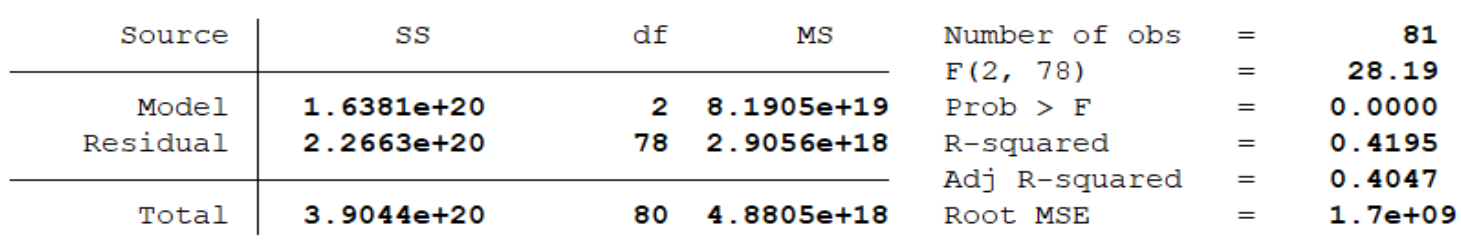

\begin{tabular}{|c|c|c|c|c|c|c|}
\hline ChangeofRevenueBD & Coef. & Std. Err. & $t$ & $P>|t|$ & [95\% Conf. & Interval] \\
\hline PriceMaker & $-2.46 e+08$ & $4.06 e+08$ & -0.61 & 0.546 & $-1.05 e+09$ & $5.61 e+08$ \\
\hline NumberofEmployees & 46768.68 & 6404.685 & 7.30 & 0.000 & 34017.93 & 59519.42 \\
\hline${ }_{-}^{\text {cons }}$ & $1.83 e+08$ & $2.98 e+08$ & 0.61 & 0.542 & $-4.11 e+08$ & $7.77 e+08$ \\
\hline
\end{tabular}




\section{$9^{\text {th }}$ INTERNATIONAL CONFERENCE ON MANAGEMENT , ECONOMICS AND HUMANITIES}

26-28 July, 2019

London, United Kingdom

regress ChangeofRevenueBD AverageNetLernerIndex

\begin{tabular}{r|crc} 
Source & SS & df & MS \\
\hline $\begin{array}{r}\text { Model } \\
\text { Residual }\end{array}$ & $\begin{array}{r}1.9473 e+19 \\
3.7097 e+20\end{array}$ & 79 & $4.6958 e+18$ \\
\hline Total & $3.9044 e+20$ & 80 & $4.8805 e+18$
\end{tabular}

Number of obs
F(1, 79)
Prob $>$ F
R-squared
Adj R-squared
Root MSE

$\begin{array}{rr}= & 81 \\ = & 4.15 \\ = & 0.0451 \\ = & 0.0499 \\ = & 0.0378 \\ = & 2.2 e+09\end{array}$

\begin{tabular}{|c|c|c|c|c|c|c|}
\hline ChangeofRevenueBD & Coef. & Std. Err. & $t$ & $P>|t|$ & [95\% Conf. & Interval] \\
\hline AverageNetLernerIndex & $5.56 e+09$ & $2.73 e+09$ & 2.04 & 0.045 & $1.26 \mathrm{e}+08$ & $1.10 \mathrm{e}+10$ \\
\hline$-^{\text {cons }}$ & $5.84 e+08$ & $2.67 e+08$ & 2.19 & 0.031 & $5 \cdot 34 e+07$ & 1.11e+09 \\
\hline
\end{tabular}

regress ChangeofRevenueBD AverageNetIernerIndex NumberofEmployees

\begin{tabular}{|c|c|c|c|c|c|c|}
\hline Source & SS & $d f$ & MS & Number of obs & $=$ & 81 \\
\hline & & & & $E(2,78)$ & $=$ & 28.51 \\
\hline Model & $1.6490 \mathrm{e}+20$ & 2 & 8. 2451e+19 & Prob $>E$ & $=$ & 0.0000 \\
\hline Residual & $2.2554 e+20$ & 78 & $2.8916 e+18$ & $\mathrm{R}$-squared & $=$ & 0.4223 \\
\hline & & & & Adj R-squared & $=$ & 0.4075 \\
\hline Total & $3.9044 e+20$ & 80 & $4.8805 e+18$ & Root MSE & $=$ & 1. $7 e+09$ \\
\hline
\end{tabular}

\begin{tabular}{|c|c|c|c|c|c|c|}
\hline ChangeofRevenueBD & Coef. & Std. Err. & $t$ & $P>|t|$ & [95\% Conf. & Interval] \\
\hline AveragenetLernerIndex & 1. $91 e+09$ & $2.21 e+09$ & 0.86 & 0.390 & $-2.48 e+09$ & $6.30 e+09$ \\
\hline NumberofEmployees & 44298.44 & 6246.375 & 7.09 & 0.000 & 31862.86 & 56734.02 \\
\hline$-^{\text {cons }}$ & -1536422 & $2.25 e+08$ & -0.01 & 0.995 & $-4.49 e+08$ & $4.46 e+08$ \\
\hline
\end{tabular}


$9^{\text {th }}$ INTERNATIONAL CONFERENCE ON MANAGEMENT , ECONOMICS AND HUMANITIES 26-28 July, 2019 London, United Kingdom

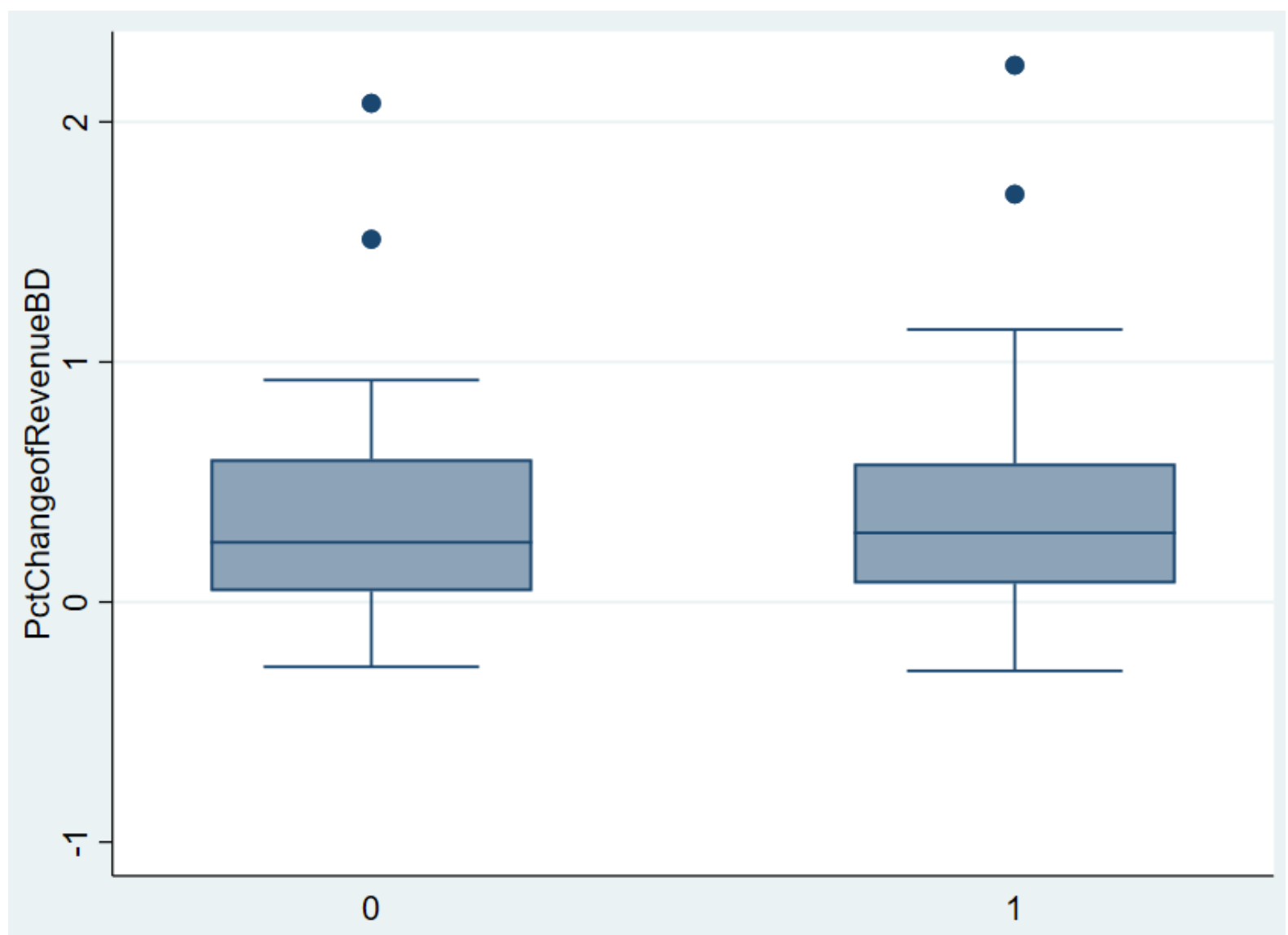




\section{$9^{\text {th }}$ INTERNATIONAL CONFERENCE ON MANAGEMENT , ECONOMICS AND HUMANITIES}

26-28 July, 2019

London, United Kingdom

- regress PctChangeofRevenueBD PriceMaker

\begin{tabular}{r|rrr} 
Source & SS & df & MS \\
\hline Model & .024644673 & 1 & .024644673 \\
Residual & 18.4438329 & 79 & .233466239 \\
\hline Total & 18.4684775 & 80 & .230855969
\end{tabular}

Number of obs

$\mathrm{F}(1,79)$

Prob > E

R-squared

Adj R-squared

Root MSE
$=81$

0.11

0.7461

0.0013

$-0.0113$

.48318

\begin{tabular}{|c|c|c|c|c|c|c|}
\hline PctChan ueBD & Coef. & std. Err. & $t$ & $P>|t|$ & [95\% Conf. & Interval] \\
\hline Pricemaker & .0354998 & .109264 & 0.32 & 0.746 & -.1819846 & .2529843 \\
\hline$-^{\text {cons }}$ & .3540257 & .0841114 & 4.21 & 0.000 & .1866061 & .5214454 \\
\hline
\end{tabular}

regress PctChangeofRevenueBD PriceMaker NumberofEmployees

\begin{tabular}{|c|c|c|c|c|c|c|}
\hline Source & SS & $d f$ & MS & Number of obs & $=$ & 81 \\
\hline Model & .56190599 & 2 & .280952995 & Prob > F & $=$ & 0.2997 \\
\hline Residual & 17.9065715 & 78 & .22957143 & $\mathrm{R}$-squared & $=$ & 0.0304 \\
\hline & & & & Adj R-squared & $=$ & 0.0056 \\
\hline Total & 18.4684775 & 80 & .230855969 & Root MSE & $=$ & .47914 \\
\hline
\end{tabular}

\begin{tabular}{|c|c|c|c|c|c|c|}
\hline PctChangeofReve D & coef. & std. Err. & $t$ & $P>|t|$ & [95\% Conf. & Interval] \\
\hline Pricemaker & .0896614 & .1139865 & 0.79 & 0.434 & -.1372683 & .3165911 \\
\hline NumberofEmployees & $-2.75 e-06$ & $1.80 e-06$ & -1.53 & 0.130 & $-6.34 e-06$ & $8.30 e-07$ \\
\hline _cons & .3678699 & .0838964 & 4.38 & 0.000 & .200845 & .5348949 \\
\hline
\end{tabular}




\section{$9^{\text {th }}$ INTERNATIONAL CONFERENCE ON MANAGEMENT , ECONOMICS AND HUMANITIES}

26-28 July, 2019

London, United Kingdom

- regress PctChangeofRevenueBD AverageNetIernerIndex

\begin{tabular}{r|crc} 
Source & SS & df & MS \\
\hline $\begin{array}{r}\text { Model } \\
\text { Residual }\end{array}$ & $\begin{array}{r}.055331512 \\
18.413146\end{array}$ & $\begin{array}{r}1 \\
.055331512 \\
.233077798\end{array}$ \\
\hline Total & 18.4684775 & 80 & .230855969
\end{tabular}

$\begin{array}{llr}\text { Number of obs } & = & 81 \\ \text { F }(1,79) & = & 0.24 \\ \text { Prob }>\text { F } & = & 0.6274 \\ \text { R-squared } & = & 0.0030 \\ \text { Adj R-squared } & = & -0.0096 \\ \text { Root MSE } & = & .48278\end{array}$

\begin{tabular}{|c|c|c|c|c|c|c|}
\hline PctChangeofRevenueBD & Coef. & std. Err. & $t$ & $P>|t|$ & [95\% Conf. & Interval] \\
\hline AveragenetLernerIndex & .2966206 & .6087872 & 0.49 & 0.627 & -.91514 & 1.508381 \\
\hline$-{ }^{\text {cons }}$ & .362632 & .0594005 & 6.10 & 0.000 & .2443983 & .4808656 \\
\hline
\end{tabular}

- regress PctChangeofRevenueBD AverageNetLernerIndex Numberofmployees

\begin{tabular}{|c|c|c|c|c|c|c|}
\hline Source & SS & df & MS & \multirow{2}{*}{$\begin{array}{l}\text { Number of obs } \\
\mathrm{E}(2,78)\end{array}$} & $=$ & \multirow{2}{*}{$\begin{array}{r}81 \\
1.26\end{array}$} \\
\hline & & & & & $=$ & \\
\hline Model & .578080999 & 2 & .289040499 & Prob $>\mathrm{F}$ & $=$ & 0.2893 \\
\hline Residual & 17.8903965 & 78 & .229364058 & $\mathrm{R}$-squared & $=$ & 0.0313 \\
\hline & & & & Adj R-squared & $=$ & 0.0065 \\
\hline Total & 18.4684775 & 80 & .230855969 & Root MSE & $=$ & .47892 \\
\hline
\end{tabular}

\begin{tabular}{|c|c|c|c|c|c|c|}
\hline PctChangeofRevenueBD & Coef. & Std. Err. & $t$ & $P>|t|$ & [95\% Conf. & Interval] \\
\hline AveragenetLernerIndex & .515886 & .621137 & 0.83 & 0.409 & -.7207029 & 1.752475 \\
\hline NumberofEmployees & $-2.66 e-06$ & $1.76 e-06$ & $-1 \cdot 51$ & 0.135 & $-6.16 e-06$ & $8.46 e-07$ \\
\hline Cons $^{\mathrm{con}}$ & .3977452 & .0633495 & 6.28 & 0.000 & .2716259 & .5238644 \\
\hline
\end{tabular}

\section{Appendix B}

Change in net income in DA stage 
$9^{\text {th }}$ INTERNATIONAL CONFERENCE ON
MANAGEMENT , ECONOMICS AND HUMANITIES

26-28 July, 2019

London, United Kingdom

regress ChangeofNetIncomedA PriceMaker

\begin{tabular}{|c|c|c|c|c|c|c|}
\hline Source & SS & df & MS & Number of obs & $=$ & 81 \\
\hline & & & & $\mathrm{F}(1,79)$ & $=$ & 5.83 \\
\hline Model & $2.1608 e+17$ & 1 & $2.1608 e+17$ & Prob > F & $=$ & 0.0181 \\
\hline Residual & $2.9284 e+18$ & 79 & $3.7069 e+16$ & R-squared & $=$ & 0.0687 \\
\hline Total & $3.1445 e+18$ & 80 & 3. $9306 \mathrm{e}+16$ & Root MSE & $=$ & 1. $9 e+08$ \\
\hline
\end{tabular}

\begin{tabular}{r|rrrrrr}
\hline ChangeofNe A & Coef. & Std. Err. & $t$ & P $>|t|$ & {$[95 \%$ Conf. Interval] } \\
\hline PriceMaker & $1.05 e+08$ & $4.35 e+07$ & 2.41 & 0.018 & $1.85 e+07$ & $1.92 e+08$ \\
Cons & $1.82 e+07$ & $3.35 e+07$ & 0.54 & 0.589 & $-4.86 e+07$ & $8.49 e+07$ \\
\hline
\end{tabular}

regress ChangeofNetIncomeDA PriceMaker NumberofEmployees

\begin{tabular}{|c|c|c|c|c|c|c|}
\hline Source & SS & df & MS & Number of obs & $=$ & 81 \\
\hline Model & $2.6635 e+17$ & 2 & 1. $3317 e+17$ & Prob > F & $=$ & 0.0317 \\
\hline Residual & $2.8782 e+18$ & 78 & $3.6900 \mathrm{e}+16$ & $\mathrm{R}$-squared & $=$ & 0.0847 \\
\hline Total & $3.1445 e+18$ & 80 & 3. $9306 \mathrm{e}+16$ & $\begin{array}{l}\text { Ad] R-Squared } \\
\text { Root MSE }\end{array}$ & $\begin{array}{l}= \\
=\end{array}$ & $1.9 e+08$ \\
\hline
\end{tabular}

\begin{tabular}{r|rrrrrr}
\hline ChangeofNetInco A & Coef. & Std. Err. & $t$ & P $>|t|$ & [95\% Conf. Interval] \\
\hline PriceMaker & $\mathbf{8 . 9 5 e + 0 7}$ & $\mathbf{4 . 5 4 e + 0 7}$ & 1.97 & 0.052 & $\mathbf{- 9 6 6 6 6 1 . 3}$ & $1.80 e+08$ \\
NumberofEmployees & 631.6667 & $\mathbf{5 4 1 . 1 9 2 2}$ & 1.17 & 0.247 & $\mathbf{- 4 4 5 . 7 6 4 1}$ & 1709.098 \\
_Cons & $1.48 \mathrm{e}+07$ & $3.36 \mathrm{e}+07$ & 0.44 & 0.660 & $\mathbf{- 5 . 2 0 e + 0 7}$ & $\mathbf{8 . 1 7 e + 0 7}$ \\
\hline
\end{tabular}




\section{$9^{\text {th }}$ INTERNATIONAL CONFERENCE ON MANAGEMENT , ECONOMICS AND HUMANITIES}

26-28 July, 2019

London, United Kingdom

regress ChangeofNetIncomeDA AverageNetIernerIndex

\begin{tabular}{|c|c|c|c|c|c|c|}
\hline Source & SS & $\mathrm{df}$ & MS & Number of obs & $=$ & 81 \\
\hline & & & & $\mathrm{F}(1,79)$ & $=$ & 2.50 \\
\hline Model & $9.6413 e+16$ & 1 & $9.6413 e+16$ & Prob > F & $=$ & 0.1179 \\
\hline Residual & $3.0481 e+18$ & 79 & $3.8584 e+16$ & R-squared & $=$ & 0.0307 \\
\hline & & & & Adj R-squared & $=$ & 0.0184 \\
\hline Total & $3.1445 e+18$ & 80 & 3. $9306 e+16$ & Root MSE & $=$ & $2.0 e+08$ \\
\hline
\end{tabular}

\begin{tabular}{|c|c|c|c|c|c|c|}
\hline ChangeofNetIncomeDA & Coef. & Std. Err. & $t$ & $P>|t|$ & [95\% Conf. & Interval] \\
\hline AverageNetLernerIndex & $3.92 e+08$ & $2.48 e+08$ & 1.58 & 0.118 & $-1.01 e+08$ & $8.85 e+08$ \\
\hline$-^{\text {cons }}$ & $6.40 \mathrm{e}+07$ & $2.42 e+07$ & 2.65 & 0.010 & $1.59 e+07$ & $1.12 \mathrm{e}+08$ \\
\hline
\end{tabular}

- regress ChangeofNetIncomedA AverageNetIernerIndex NumberofEmployees

\begin{tabular}{|c|c|c|c|c|c|c|}
\hline Source & SS & df & MS & Number of obs & $=$ & 81 \\
\hline & & & & $\mathrm{F}(2,78)$ & & 2.33 \\
\hline Model & $1.7740 \mathrm{e}+17$ & 2 & 8.8701e+16 & Prob $>\mathrm{F}$ & $=$ & 0.1039 \\
\hline Residual & $2.9671 e+18$ & 78 & $3.8040 \mathrm{e}+16$ & $\mathrm{R}$-squared & $=$ & 0.0564 \\
\hline & & & & Adj $\mathrm{R}$-squared & $=$ & 0.0322 \\
\hline Total & $3.1445 e+18$ & 80 & $3.9306 e+16$ & Root MSE & $=$ & $2.0 e+08$ \\
\hline
\end{tabular}

\begin{tabular}{|c|c|c|c|c|c|c|}
\hline ChangeofNetIncomeDA & Coef. & Std. Err. & $t$ & $P>|t|$ & {$[95 \%$ Conf. } & Interval] \\
\hline AverageNetLernerIndex & $3.02 e+08$ & $2.53 e+08$ & 1.19 & 0.236 & $-2.02 e+08$ & $8.07 e+08$ \\
\hline NumberofEmployees & 789.5716 & 541.1217 & 1.46 & 0.149 & -287.719 & 1866.862 \\
\hline$-^{\text {cons }}$ & $5.21 e+07$ & $2.54 e+07$ & 2.05 & 0.043 & 1581979 & $1.03 e+08$ \\
\hline
\end{tabular}


$9^{\text {th }}$ INTERNATIONAL CONFERENCE ON MANAGEMENT , ECONOMICS AND HUMANITIES 26-28 July, 2019 London, United Kingdom

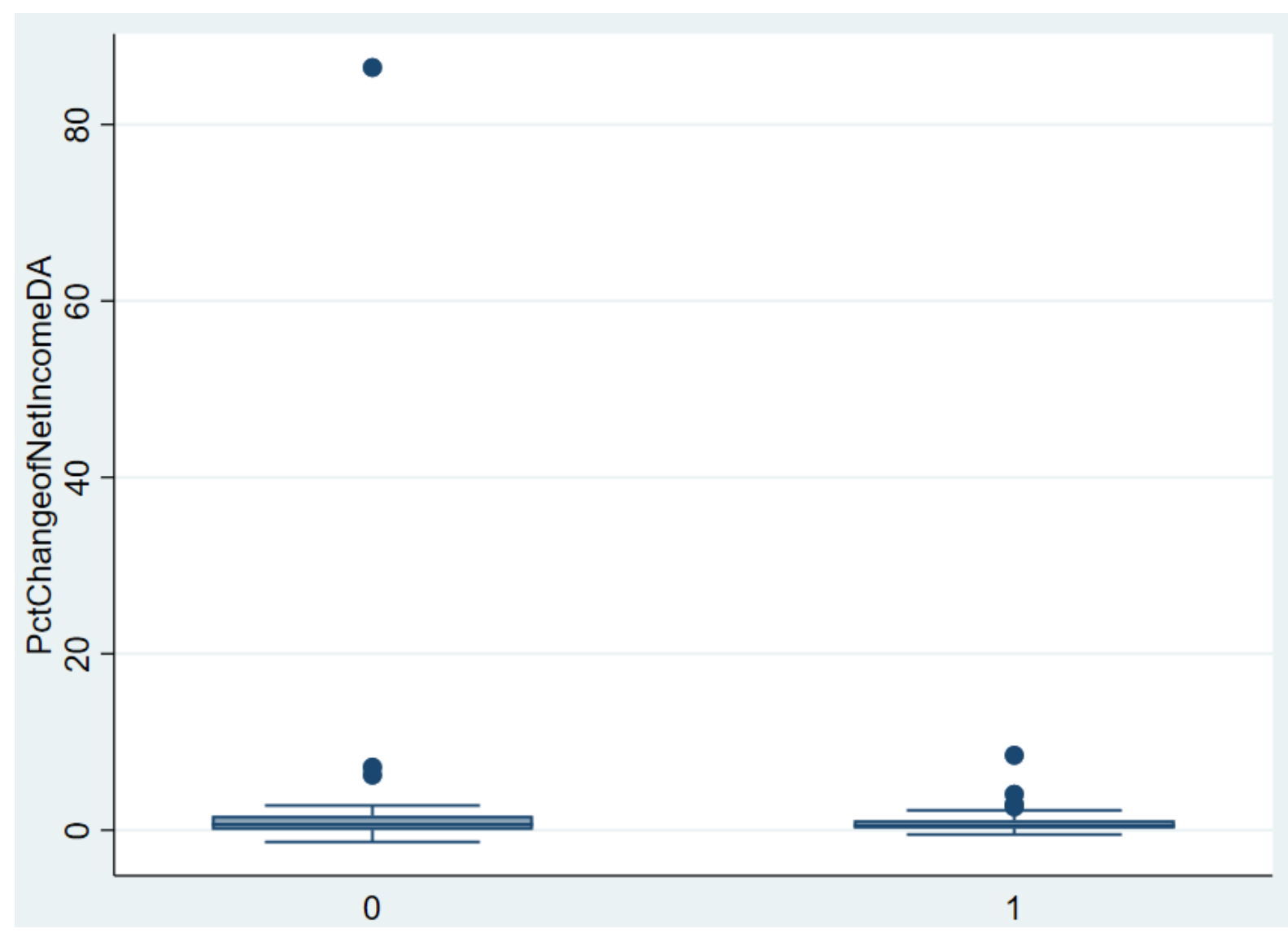




\section{$9^{\text {th }}$ INTERNATIONAL CONFERENCE ON MANAGEMENT , ECONOMICS AND HUMANITIES}

26-28 July, 2019

London, United Kingdom

regress PctChangeofNetIncomeDA PriceMaker if PctChangeofNetIncomedA $<50$

\begin{tabular}{|c|c|c|c|c|c|c|}
\hline Source & SS & df & MS & Number of obs & $=$ & \\
\hline Model & .07002447 & 1 & .07002447 & Prob $>F$ & $=$ & 0.8676 \\
\hline Residual & 195.227082 & 78 & 2.50291131 & $\mathrm{R}$-squared & $=$ & 0.0004 \\
\hline & & & & Adj R-squared & $=$ & -0.0125 \\
\hline Total & 195.297107 & 79 & 2.47211527 & Root MSE & $=$ & 1.5821 \\
\hline
\end{tabular}

\begin{tabular}{r|rrrrrr}
\hline PctChangeo A & Coef. & Std. Err. & $t$ & P $>|t|$ & [95\% Conf. Interval] \\
\hline PriceMaker & -.0603913 & .361054 & -0.17 & 0.868 & -.7791945 & .6584119 \\
_cons & .9353219 & .2796712 & 3.34 & 0.001 & .3785393 & 1.492105 \\
\hline
\end{tabular}

regress PctChangeofNetIncomeDA PriceMaker NumberofEmployees if PctChangeofNetIncomeDA<5 $>0$

\begin{tabular}{|c|c|c|c|c|c|c|}
\hline Source & SS & $\mathrm{df}$ & MS & Number of obs & $=$ & 80 \\
\hline Mode1 & 2. 91477778 & 2 & 145738889 & Prob $>\mathrm{F}$ & $=$ & 0.5605 \\
\hline Residual & 192.382329 & 77 & 2.4984718 & $\mathrm{R}$-squared & $=$ & 0.0149 \\
\hline & & & & Adj $R$-squared & $=$ & -0.0107 \\
\hline Total & 195.297107 & 79 & 2.47211527 & Root MSE & $=$ & 1.5807 \\
\hline
\end{tabular}

\begin{tabular}{|c|c|c|c|c|c|c|}
\hline PctChangeofNetI $\sim \mathrm{A}$ & Coef. & std. Err. & $t$ & $P>|t|$ & {$[95 \%$ Conf. } & Interval] \\
\hline PriceMaker & .0583093 & .3774963 & 0.15 & 0.878 & -.6933819 & .8100004 \\
\hline NumberofEmployees & $-4.75 e-06$ & $4.45 e-06$ & -1.07 & 0.289 & -.0000136 & $4.12 e-06$ \\
\hline${ }^{\mathrm{cons}}$ & .9589861 & .2803018 & 3.42 & 0.001 & .400834 & 1. 517138 \\
\hline
\end{tabular}




\section{$9^{\text {th }}$ INTERNATIONAL CONFERENCE ON MANAGEMENT , ECONOMICS AND HUMANITIES}

26-28 July, 2019

London, United Kingdom

regress PctChangeofNetIncomeDA AverageNetLernerIndex if PctChangeofNetIncomeDA $<50$

\begin{tabular}{r|rrr} 
Source & SS & df & MS \\
\hline $\begin{array}{r}\text { Model } \\
\text { Residual }\end{array}$ & $\begin{array}{r}.018362574 \\
195.278744\end{array}$ & 1 & .018362574 \\
\hline Total & 195.297107 & 79 & 2.50357364 \\
\hline
\end{tabular}

Number of obs

$\mathrm{F}(1,78)$

Prob > F

R-squared

Adj R-squared $=-0.0127$

Root MSE $\quad=1.5823$

\begin{tabular}{|c|c|c|c|c|c|c|}
\hline PctChangeofNet Incom $\sim \mathrm{A}$ & Coef. & Std. Err. & $t$ & $P>|t|$ & {$[95 \%$ Conf. } & Interval] \\
\hline AverageNetLernerIndex & .171004 & 1.996731 & 0.09 & 0.932 & -3.804182 & 4.14619 \\
\hline$-^{\text {cons }}$ & .8918557 & .1960218 & 4.55 & 0.000 & .5016063 & 1.282105 \\
\hline
\end{tabular}

- regress PctChangeofNetIncomeDA AverageNetLernerIndex NumberofEmployees if PctChangeofNe

$>$ tIncomeDA $<50$

\begin{tabular}{|c|c|c|c|c|c|c|}
\hline Source & SS & df & MS & Number of obs & $=$ & 80 \\
\hline Model & 3.16678229 & 2 & 1.58339115 & Prob $>\mathrm{F}$ & $=$ & 0.5329 \\
\hline Residual & 192.130324 & 77 & 2.49519902 & $\mathrm{R}$-squared & $=$ & 0.0162 \\
\hline & & & & Adj R-squared & $=$ & -0.0093 \\
\hline Total & 195.297107 & 79 & 2.47211527 & Root MSE & $=$ & 1.5796 \\
\hline
\end{tabular}

\begin{tabular}{|c|c|c|c|c|c|c|}
\hline PctChangeofNetIncom $\sim \mathrm{A}$ & Coef. & Std. Err. & t & $P>|t|$ & [95\% Conf. & Interval] \\
\hline AverageNetLernerIndex & .7257442 & 2.053652 & 0.35 & 0.725 & -3.3636 & 4.815088 \\
\hline NumberofEmployees & $-4.92 e-06$ & $4.38 e-06$ & -1.12 & 0.265 & -.0000137 & $3.80 e-06$ \\
\hline${ }_{-}^{\text {cons }}$ & .9666682 & .2067165 & 4.68 & 0.000 & .5550431 & 1.378293 \\
\hline
\end{tabular}




\section{$9^{\text {th }}$ INTERNATIONAL CONFERENCE ON MANAGEMENT , ECONOMICS AND HUMANITIES}

26-28 July, 2019

\section{Appendix C}

Change in revenue in DA stage

. regress ChangeofRevenueDA PriceMaker

\begin{tabular}{|c|c|c|c|c|c|c|}
\hline Source & SS & df & MS & Number of obs & $=$ & 81 \\
\hline Model & $2.5407 e+19$ & 1 & $2.5407 e+19$ & Prob > F & $=$ & 0.0581 \\
\hline Residual & $5.4272 e+20$ & 79 & $6.8699 e+18$ & $\mathrm{R}$-squared & $=$ & 0.0447 \\
\hline & & & & Adj R-squared & $=$ & 0.0326 \\
\hline Total & $5.6813 e+20$ & 80 & $7.1016 \mathrm{e}+18$ & Root MSE & $=$ & $2.6 e+09$ \\
\hline
\end{tabular}

\begin{tabular}{r|rrrrrr}
\hline ChangeofRe A & Coef. & Std. Err. & $t$ & P $>|t|$ & [95\% Conf. Interval] \\
\hline PriceMaker & $1.14 e+09$ & $5.93 e+08$ & 1.92 & 0.058 & $\mathbf{- 3 . 9 9 e + 0 7}$ & $2.32 e+09$ \\
-Cons & $6.48 e+08$ & $4.56 e+08$ & 1.42 & 0.159 & $\mathbf{- 2 . 6 0 e + 0 8}$ & $1.56 e+09$ \\
\hline
\end{tabular}

- regress ChangeofRevenueDA PriceMaker NumberofEmployees

\begin{tabular}{|c|c|c|c|c|c|c|}
\hline Source & SS & $d f$ & MS & Number of obs & $=$ & 81 \\
\hline Model & $3.7737 e+20$ & 2 & $1.8868 \mathrm{e}+20$ & Prob > F & $=$ & 0.0000 \\
\hline Residual & $1.9076 \mathrm{e}+20$ & 78 & $2.4456 \mathrm{e}+18$ & R-squared & $=$ & 0.6642 \\
\hline Total & $5.6813 e+20$ & 80 & $7.1016 \mathrm{e}+18$ & $\begin{array}{l}\text { Adj R-squared } \\
\text { Root MSE }\end{array}$ & $\begin{array}{l}= \\
=\end{array}$ & $\begin{array}{l}0.6556 \\
1.6 e+09\end{array}$ \\
\hline
\end{tabular}

\begin{tabular}{r|rrrrrr}
\hline ChangeofRevenueDA & Coef. & Std. Err. & $t$ & P $>|t|$ & [95\% Conf. Interval] \\
\hline PriceMaker & $\mathbf{- 1 . 6 6 e + 0 8}$ & $\mathbf{3 . 7 0 e + 0 8}$ & $\mathbf{- 0 . 4 5}$ & 0.656 & $\mathbf{- 9 . 0 2 e + 0 8}$ & $\mathbf{5 . 7 1 e + 0 8}$ \\
NumberofEmployees & $\mathbf{5 2 8 5 5 . 2 5}$ & $\mathbf{4 4 0 5 . 8 9 6}$ & 12.00 & 0.000 & $\mathbf{4 4 0 8 3 . 7 9}$ & $\mathbf{6 1 6 2 6 . 7 2}$ \\
_Cons & $\mathbf{3 . 7 1 e + 0 8}$ & $\mathbf{2 . 7 3 e + 0 8}$ & 1.36 & 0.179 & $\mathbf{- 1 . 7 3 e + 0 8}$ & $\mathbf{9 . 1 5 e + 0 8}$ \\
\hline
\end{tabular}




\section{$9^{\text {th }}$ INTERNATIONAL CONFERENCE ON MANAGEMENT , ECONOMICS AND HUMANITIES}

26-28 July, 2019

London, United Kingdom

- regress ChangeofRevenueDA AverageNetLernerIndex

\begin{tabular}{|c|c|c|c|c|c|c|}
\hline Source & SS & df & MS & Number of obs & $=$ & 81 \\
\hline Model & $3.7808 \mathrm{e}+19$ & 1 & $3.7808 e+19$ & Prob > F & $=$ & 0.0201 \\
\hline Residual & $5.3032 e+20$ & 79 & $6.7129 e+18$ & R-squared & $=$ & 0.0665 \\
\hline tal & $5.6813 e+20$ & 80 & $7.1016 \mathrm{e}+18$ & $\begin{array}{l}\text { Adj R-squared } \\
\text { Root MSE }\end{array}$ & $\begin{array}{l}= \\
=\end{array}$ & $\begin{array}{l}0.0547 \\
2.6 e+09\end{array}$ \\
\hline
\end{tabular}

\begin{tabular}{|c|c|c|c|c|c|c|}
\hline ChangeofRevenueDA & Coef. & Std. Err. & t & $P>|t|$ & [95\% Conf. & Interval] \\
\hline AverageNetLernerIndex & $7.75 e+09$ & $3.27 e+09$ & 2.37 & 0.020 & $1.25 e+09$ & 1. $43 e+10$ \\
\hline _cons & $9.99 e+08$ & $3.19 e+08$ & 3.13 & 0.002 & $3.64 e+08$ & $1.63 e+09$ \\
\hline
\end{tabular}

- regress ChangeofRevenueDA AverageNetIernerIndex NumberofEmployees

\begin{tabular}{|c|c|c|c|c|c|c|}
\hline Source & SS & df & MS & Number of obs & $=$ & 81 \\
\hline Model & $3.7918 e+20$ & 2 & 1. $8959 \mathrm{e}+20$ & Prob > F & $=$ & 0.0000 \\
\hline Residual & $1.8895 e+20$ & 78 & $2.4224 e+18$ & $\mathrm{R}$-squared & $=$ & 0.6674 \\
\hline Total & $5.6813 e+20$ & 80 & $7.1016 e+18$ & $\begin{array}{l}\text { Ad] R-squared } \\
\text { Root MSE }\end{array}$ & $\begin{array}{l}= \\
=\end{array}$ & $\begin{array}{l}0.6589 \\
1.6 e+09\end{array}$ \\
\hline
\end{tabular}

\begin{tabular}{|c|c|c|c|c|c|c|}
\hline ChangeofRevenueDA & Coef. & Std. Err. & $t$ & $P>|t|$ & {$[95 \%$ Conf. } & Interval] \\
\hline AverageNetLernerIndex & $1.97 e+09$ & $2.02 e+09$ & 0.97 & 0.333 & $-2.05 e+09$ & $6.00 e+09$ \\
\hline NumberofEmployees & 51261.31 & 4318.138 & 11.87 & 0.000 & 42664.56 & 59858.06 \\
\hline$-^{\text {cons }}$ & $2.22 e+08$ & $2.02 e+08$ & 1.10 & 0.276 & $-1.81 e+08$ & $6.25 e+08$ \\
\hline
\end{tabular}


$9^{\text {th }}$ INTERNATIONAL CONFERENCE ON MANAGEMENT , ECONOMICS AND HUMANITIES 26-28 July, 2019 London, United Kingdom

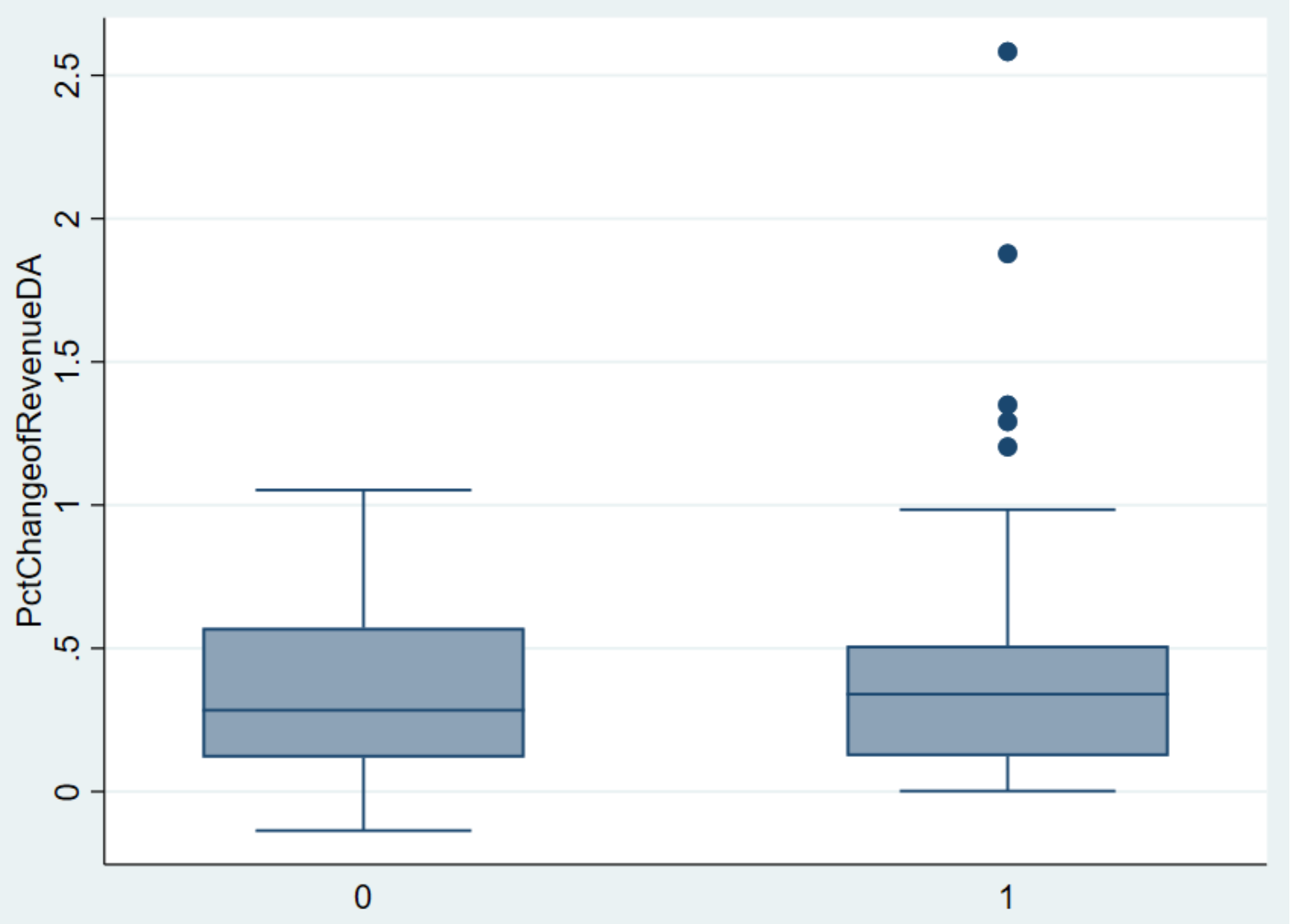




\section{$9^{\text {th }}$ INTERNATIONAL CONFERENCE ON MANAGEMENT , ECONOMICS AND HUMANITIES}

26-28 July, 2019

London, United Kingdom

- regress PctChangeofRevenueDA PriceMaker

\begin{tabular}{|c|c|c|c|c|c|c|}
\hline Source & SS & df & MS & Number of obs & $=$ & 81 \\
\hline & & & & $\mathrm{E}(1,79)$ & $=$ & 1.36 \\
\hline Model & .255024066 & 1 & .255024066 & Prob > F & $=$ & 0.2464 \\
\hline Residual & 14.7710187 & 79 & .186974921 & R-squared & $=$ & 0.0170 \\
\hline & & & & Adj $\mathrm{R}$-squared & $=$ & 0.0045 \\
\hline Total & 15.0260428 & 80 & .187825535 & Root MSE & $=$ & .43241 \\
\hline
\end{tabular}

\begin{tabular}{r|rrrrrr}
\hline PctChan ueDA & Coef. & Std. Err. & $t$ & P $>|t|$ & [95\% Conf. Interval] \\
\hline PriceMaker & .1141972 & .0977815 & 1.17 & 0.246 & -.080432 & .3088264 \\
_cons & .3483019 & .0752722 & 4.63 & 0.000 & .1984763 & .4981275 \\
\hline
\end{tabular}

regress PctChangeofRevenueDA PriceMaker Numberofmmployees

\begin{tabular}{|c|c|c|c|c|c|c|}
\hline Source & sS & df & MS & Number of obs & $=$ & 81 \\
\hline & & & & & & \\
\hline Model & .625045393 & 2 & .312522697 & Prob > F & $=$ & 0.1907 \\
\hline Residual & 14.4009974 & 78 & .184628172 & R-squared & $=$ & 0.0416 \\
\hline & & & & Adj R-squared & $=$ & 0.0170 \\
\hline Total & 15.0260428 & 80 & .187825535 & Root MSE & $=$ & .42968 \\
\hline
\end{tabular}

\begin{tabular}{|c|c|c|c|c|c|c|}
\hline PctChangeofReve $\mathrm{A}$ & Coef. & std. Err. & $t$ & $P>|t|$ & {$[95 \%$ Conf. } & Interval] \\
\hline PriceMaker & .1565251 & .1016621 & 1.54 & 0.128 & -.0458686 & .3589189 \\
\hline NumberofEmployees & $-1.71 e-06$ & $1.21 e-06$ & -1.42 & 0.161 & $-4.12 e-06$ & $6.96 e-07$ \\
\hline$-^{\text {cons }}$ & .3573023 & .0750681 & 4.76 & 0.000 & .2078533 & .5067514 \\
\hline
\end{tabular}

